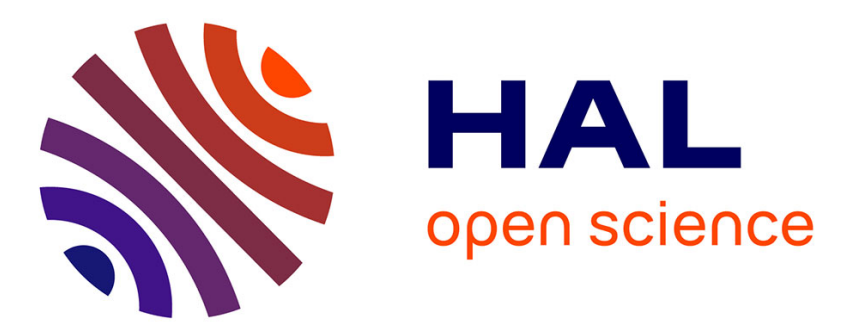

\title{
A new Evaluation and Decision Making Framework Investigating the Elimination-by-Aspects Model in the Context of Transportation Projects' Investment Choices
}

Rayan Khraibani, André de Palma, Nathalie Picard, Isam Kaysi

\section{- To cite this version:}

Rayan Khraibani, André de Palma, Nathalie Picard, Isam Kaysi. A new Evaluation and Decision Making Framework Investigating the Elimination-by-Aspects Model in the Context of Transportation Projects' Investment Choices. 2016. hal-01292490

\author{
HAL Id: hal-01292490 \\ https://hal.science/hal-01292490 \\ Preprint submitted on 23 Mar 2016
}

HAL is a multi-disciplinary open access archive for the deposit and dissemination of scientific research documents, whether they are published or not. The documents may come from teaching and research institutions in France or abroad, or from public or private research centers.
L'archive ouverte pluridisciplinaire HAL, est destinée au dépôt et à la diffusion de documents scientifiques de niveau recherche, publiés ou non, émanant des établissements d'enseignement et de recherche français ou étrangers, des laboratoires publics ou privés. 


\title{
ECOLE POLYTECHNIQUE
}

\section{A New Evaluation and Decision Making Framework Investigating the Elimination-by- Aspects Model in the Context of Transportation Projects' Investment Choices}

\author{
Rayan KHRAIBANI \\ André DE PALMA \\ Nathalie PICARD \\ Isam KAYSI
}

March, 2016

Cahier $\mathrm{n}^{\circ}$ 2016-02

\section{DEPARTEMENT D'ECONOMIE}

Route de Saclay

91128 PALAISEAU CEDEX

(33) 169333033

http://www.economie.polytechnique.edu/

mariame.seydi@polytechnique.edu 


\title{
A New Evaluation and Decision Making Framework Investigating the Elimination-by-Aspects Model in the Context of Transportation Projects' Investment Choices
}

\author{
R. Khraibani ${ }^{a, 1}$, A. de Palma ${ }^{\text {b }}$, N. Picard ${ }^{\mathrm{c}}$, I. Kaysi ${ }^{\mathrm{d}}$ \\ ${ }^{a}$ Université Cergy Pontoise, 33 Boulevard du Port, 95000 Cergy-Pontoise, France ; rayan.khraibani@gmail.com \\ ${ }^{b}$ ENS-Cachan 61 Avenue du Président Wilson, 94230 Cachan, France; andre.depalma@ens-cachan.fr \\ ${ }^{c}$ Université Cergy Pontoise, 33 Boulevard du Port, 95000 Cergy-Pontoise, France ; nathalie.picard@u-cergy.fr \\ ${ }^{d}$ American University of Beirut, P.O. Box 11-0236, Riad El-Solh / Beirut, Lebanon; isam@aub.edu.lb
}

\begin{abstract}
The Transportation Elimination-by-Aspects (TEBA) framework, a new evaluation and decision making framework (and methodology) for large transportation projects, is proposed to elicit, structure and quantify the preferences of stakeholder groups across project alternatives. The decision rule used for group decision making within TEBA is the individual non-compensatory model of choice elimination by aspects (EBA). TEBA is designed to bring out the decision rule employed by decision makers when ranking the options presented, incorporate various criteria types and ease communication of relevant information related to options and criteria for multiple stakeholder groups. It is a platform for democratizing the decision making process. The TEBA framework was tested using a case study investigating alternative land connections between Beirut and Damascus. Key results showed that (1) stakeholders have employed EBA in making decisions, (2) a defined group of decision makers will rank options differently when provided with modified sets of criteria, (3) the public sector and general public groups ranked Impact on Employment among the top criteria, (4) the most important criterion per group from EBA was as expected; (5) the EBA analysis suggested that only 3 to 4 criteria are significant in reaching a decision; (6) aggregation of user assigned weights masked relative importance of criteria in some cases; and (7) analysis of user assigned weights and Minimum Threshold (MT) values suggest higher risk perception with increased criterion importance. Policy implications include recommendation to reach out to stakeholders for input on decisions, including the "people" but refrain from relying on criteria weights assigned by "experts" and reduce the "experts" role in decision making. Also, it is recommended to model the decision making in a probabilistic framework rather than a deterministic "one score" approach, seek to identify a consensus ranking, place particular attention on determining the values of the criteria that emerged as "top" at the evaluation stage and continue to emphasize risk measures.
\end{abstract}

Keywords: Transportation Investment, Collective Decision Making, Cost Benefit Analysis, Elimination by Aspects, Consensus Model / Joint Decision Making, Index of Dispersion, Behavioral Choice

JEL Classification Numbers: C44, C54, D72, H43, L91, R42

${ }^{1}$ Corresponding Author. Current Address: 4100 Greenbriar Dr. \#454, Houston, TX 77098; Phone: +1 8322057860 


\section{Introduction}

In recent years, non-physical communication networks have achieved revolutionary progress. Despite that, physical transport of people and goods remains a national and international need, as evidenced by facts such as annual investment in transport infrastructure in the CEE countries typically around 1-2\% of GDP (Short and Kopp 2005) and the UK announcement in 2010 of a 200 billion pounds in investments in infrastructure over the next 5 years (Sassoon 2010). Transportation investment projects are strategic endeavors with high impacts both at the macro-economic level and at the financial level given their capital intensive nature. Several alternative options are typically identified for any given project (Bristow and Nellthorp 2000). The options ${ }^{2}$ are evaluated by determining a set of criteria for evaluation and assessing the performance of each option with respect to those criteria (Adler 1987). Evaluation of options is a complex task and the reader is referred to Adler 1987, de Palma, Lindsey and Proost 2007 and de Palma, Lindsey, Quinet and Vickerman 2013 for details. A preferred option (or a ranking of available options) is determined based on the results of the evaluation, e.g. Cost Benefit Analysis (CBA) (Small 1998). The decision making model that governs this latter step in the process has been insufficiently researched (Sayers, Jessop and Hills 2003, Priemus and Bert Van Wee 2007). Moreover, fit-for-purpose criteria and risk measures, accounting for multiple stakeholder views, as well as ability for synthesizing a decision from multiple groups' decisions remain challenges within the current process despite work by de Palma, Picard and Andrieu 2009, Berechman 2009, Salling and Banister 2009, etc. The purpose of this paper is to address some of these issues: We propose an evaluation and decision making framework to elicit, structure and quantify the preferences of stakeholder groups across project alternatives.

The most common decision making methods are CBA, when only monetizable criteria are considered, and/or some form of Multi-Criteria Decision Analysis (MCDA) procedure. The MCDA methods reported to have the most success include Linear Additive Models (Keeney and Raiffa 1976), Analytical Hierarchical Process (AHP) (Saaty 1980) and multi-attribute utility theory (MAUT) (Sayers et al. 2003, Quinet 2000). The generally applied paradigm in the literature and in practice is clearly one of relative weighing and arithmetic aggregation (Tsamboulas 2007, Sayers et al. 2003). Some of the key issues that were highlighted with such approaches include inconsistency and lack of transparency in understanding the underlying logic leading to a decision i.e. the decision rule and preferences amongst the criteria used in reaching the decision as well as the rank reversal phenomenon (DTLR Wang and Luo 2009).

\footnotetext{
${ }^{2}$ For example, in order to connect 2 points $\mathrm{A}$ and $\mathrm{B}$, the options include: different highway routes, different rail routes and technologies, air transport, sea transport. As another example, consider prioritizing independent developments competing for funds; the options in this case could include. a highway project, an urban roads network upgrade, a metro system.
} 
Additional challenges to a wider application of the more popular linear additive and analytical hierarchy models in the context of transportation investment project selection include the need for alternatives to be settled in weak preference relation, the need for any two parameters to be in a constant relative compensation and the need for basic parameters to be monotonous (Cundric, Kern and Rajkovic 2008).

The DEX model (Cundric et al. 2008) and the work by Nellthorp and Mackie (Nellthorp and Mackie 2000) are noted attempts to overcome these challenges. However, the DEX falls short in responding to several critics such as its low sensitivity to small differences between alternatives and weakened transparency and increased effort in dealing with larger numbers of options and Nelthorp and Mackie's model does not deal with the aggregation of preferences.

Based on our review of the latest attempts at improving decision making frameworks, our understanding of the key characteristics required in a decision model for transportation investments decision making, and our understanding of the Elimination By Aspects (EBA) model characteristics and methods described in more detail in Section 2, this paper presents the Transportation Elimination-by-Aspects (TEBA) framework, a new evaluation and decision making framework (and methodology) for large transportation projects. TEBA is not an attempt to replace CBA. Rather, it takes CBA a step forward. CBA does not say how to aggregate multi-dimensional preferences. TEBA is one way to do so. TEBA is proposed to elicit, structure and quantify the preferences of stakeholder groups across project alternatives. The decision rule used for group decision making within TEBA is the individual non-compensatory model of choice EBA. TEBA is designed to bring out the decision rule employed by decision makers when ranking the options presented, incorporate various criteria types and ease communication of relevant information related to options and criteria for multiple stakeholder groups. It is a platform for democratizing the decision making process. The TEBA framework is tested using a case study investigating alternative land connections between Beirut and Damascus. The case study is used to analyze and compare, across three key stakeholder groups including the Public Sector, the Private Sector and the General Public groups (i) options rankings, (ii) criteria preferences, and (iii) a consensus ranking of options.

The next section elaborates on the EBA model. Section 3 describes the TEBA framework. Section 4 presents a case study application of the TEBA framework and walks the reader through details of TEBA implementation as well as results from that case study. Section 5 concludes with key insights, contributions and policy implications. 


\section{The Elimination-by-Aspects Model}

The elimination by aspects model discussed here offers a non-compensatory probabilistic alternative to existing decision models of choice. Non-compensatory models are very important, and have received very little attention in Transportation. Our approach:

- $\quad$ uses the concept of minimally acceptable levels of attributes proposed by Simon (1955) and (Young 1984),

- uses a lexicographic approach to decision making while relaxing the requirements of a priori ordering of alternatives,

- generalizes the choice model of Luce (1959) whenever the alternatives are composed of disjoint aspects, and

- generalizes the choice model of Restle (1961), who developed the representation of choice alternatives as collections of measurable aspects, whenever only binary choice probabilities are considered (see Tversky 1972 and Ranyard 1976).

Tversky introduced EBA as "a probabilistic theory of choice, based on a covert elimination process, which accounts for observed dependencies among alternatives". It is a non-compensatory model that adopts an elimination approach to alternatives that do not meet satisfaction level of a selected aspect, starting with the most important aspects and proceeding recursively (Tversky 1972).

EBA belongs to the family of discrete choice models in that it defines a probability for the choice among available alternatives. Its decision rule is a combination of lexicographic and satisfaction rules (see the early presentations in Ben-Akiva and Lerman 1985 and Anderson, de Palma and Thisse 1992). EBA has typically been employed as a descriptive model of choice mostly popular in marketing and psychology (Fader and McAlister 1990, Wickelmaier and Schmid 2004, Laurent 2006) but has also been used in other contexts such as transportation demand analysis and residential choice (Kato and Kosuda 2008, Young 1984). Applications of EBA as a prescriptive model exist as well (Gati and Fassa 1995).

For every experiment, the process starts with a clear identification of alternatives and criteria. An alternative is a viable option that the decision maker can choose; e.g. a toll highway vs a high speed railway connection between points $\mathrm{A}$ and $\mathrm{B}$. A criterion is a measure by which an alternative may be judged; e.g. Net Present Value (NPV) or travel time. The next step is to evaluate/analyze each alternative and report the value of each criterion for each alternative in a performance matrix. For criteria that are quantifiable, a Minimum Threshold (MT) is set based on expert knowledge and is fixed thereafter or alternatively left for each individual to set prior to decision taking. The performance matrix is used as a basis to build the "utilities matrix": When a criterion meets the MT for an option, a utility scale is assigned for that criterion for that alternative; a zero is assigned otherwise. The utility scale represents the 
importance of a criterion or, more specifically, it determines the probability that the criterion is chosen to guide the elimination process.

We illustrate with a simple example. The illustrative reduced performance matrix shown in Table 2-1 includes hypothetical options, criteria, and analysis results for each criterion for each option.

Table 2-1 - EBA Example: Performance Matrix

\begin{tabular}{|c|c|c|c|c|c|}
\hline \multirow{2}{*}{ Project } & \multicolumn{5}{|c|}{ Criterion } \\
\cline { 2 - 6 } & $\mathrm{C} 1$ & $\mathrm{C} 2$ & $\mathrm{C} 3$ & $\mathrm{C} 4$ & $\mathrm{C} 5$ \\
\hline Option 1 & 100 & 5 & 12 & 7 & 10 \\
\hline Option 2 & 200 & 2 & 23 & 5 & 90 \\
\hline Option 3 & 300 & 1 & 4 & 7 & 100 \\
\hline
\end{tabular}

The EBA model formulation requires the set-up of utility matrices, which requires the assignment of a minimum thresholds (MT) vector. This is illustrated in the utility matrix in Table 2-2 for the performance table in Table 2-1.

Table 2-2 - EBA Example: Utility Matrix

\begin{tabular}{|c|c|c|c|c|c|}
\hline \multirow{2}{*}{ Project } & \multicolumn{5}{|c|}{ Criterion } \\
\cline { 2 - 6 } & $\mathrm{C}_{1}$ & $\mathrm{C} 2$ & $\mathrm{C} 3$ & $\mathrm{C} 4$ & $\mathrm{C} 5$ \\
\hline Minimum Threshold & $>\mathbf{5 0}$ & $>\mathbf{4}$ & $>\mathbf{1 0}$ & $>\mathbf{6}$ & $>\mathbf{5 0}$ \\
\hline Option 1 & $\mathrm{u}_{1}$ & $\mathrm{u}_{2}$ & $\mathrm{u}_{3}$ & $\mathrm{u}_{4}$ & 0 \\
\hline Option 2 & $\mathrm{u}_{1}$ & 0 & $\mathrm{u}_{3}$ & 0 & $\mathrm{u}_{5}$ \\
\hline Option 3 & $\mathrm{u}_{1}$ & 0 & 0 & $\mathrm{u}_{4}$ & $\mathrm{u}_{5}$ \\
\hline
\end{tabular}

Generally, for every individual decision maker, the decision process proceeds as follows:

STEP 1: identify and remove all criteria that meet (or don't meet) the thresholds for all alternatives

STEP 2: select the aspect that is most important in making a decision,

STEP 3: remove the alternatives that do not possess or meet the MT requirements of the selected aspect,

STEP 4: repeat steps 2 and 3 until either no more criteria remain to guide further alternatives elimination or only one alternative remains (Tversky 1972, Anderson et al. 1992). 
Investigating EBA as the decision rule underlying the choice processes in the TEBA framework represents a shift from the numerical weighing paradigm and models the transportation investment choice problem as a probabilistic event. EBA is selected for investigation in the TEBA framework because it is a probabilistic, non-compensatory, model of choice that generates a probability of choosing a preferred option or the probability of a preferred ranking of options at the aggregate level and overcomes compensation issues that arise from MCDA models, it has the flexibility of integrating performance measures of different natures (quantitative and qualitative) and allows for these measures to be reported in their natural units, which makes them more informative and intuitive to the user, it allows the estimation of the relative "utility scales" of the criteria, which reflect the relative importance of the criteria, for multiple groups of decision makers, and is a heuristic characterized by a favorable effort to quality ratio.

For a mathematical formulation of $\mathrm{EBA}^{3}$, we start with some definitions. Define $A$ as the set of all available alternatives; define $S \subseteq A$ as the choice set, $u$ as a nonnegative function that specifies the utility for each aspect, and $s$ as the number of aspects remaining after eliminating the aspects common to all alternatives in the choice set.

Let $S_{i}$ be the set of alternatives contained in $S$ that exhibit characteristic $i, i=1 \ldots s$. Let $u_{i}$ be the utility scale (or "utility" or "weight") for each characteristic $i, i=1 \ldots s$. According to the Luce model (Luce 1959), whenever the alternatives are composed of disjoint aspects, the probability of choosing alternative $a \in S$, with $a$ having characteristic $i$, is given by:

\section{Equation 2-1}

$P_{S}(a)=\frac{u_{i}}{\sum_{j=1}^{s} u_{j}}$

As mentioned earlier, the EBA model generalizes the Luce model. Then, according to an EBA decision strategy, with alternatives composed of joint aspects (i.e. more than one alternative exhibit the same characteristic), the probability of choosing alternative $a \in S$ is defined recursively by:

\section{Equation 2-2}

$$
P_{S}(a)=\sum_{i=1}^{s} \frac{u_{i}}{\sum_{j=1}^{s} u_{j}} P_{S_{i}}(a)
$$

\footnotetext{
${ }^{3}$ The formulation of the EBA model presented in this section is based on the work by Anderson et al. (1992).
} 
where $P_{S_{i}}(a)$ denotes the probability that $a$ be chosen from the sets $S_{i}$ of alternatives having the characteristic $i$ in common, with $i=1 \ldots$. s.

The term $\frac{u_{i}}{\sum_{j=1}^{s} u_{j}}$ represents the probability of selecting characteristic $i=1 \ldots \mathrm{s}$.

Note that whenever all characteristics are common to all alternatives in $S$, this simplifies to $P_{S}(a)=1 /|S|$, where $|S|$ represents the cardinality of $S$.

One of the key challenges to the use of the EBA model is the difficulty in estimating its parameters. We used the approach by Wickelmaier and Schmid (2004) and developed our own Matlab tool accordingly. The authors propose original methods for estimating EBA in a separate work.

\section{Proposed Evaluation and Decision Making Framework (TEBA)}

In order to formulate the decision framework, a collection of procedures needs to be specified and which defines the following items: decision maker, alternatives, attributes of alternatives, and decision rule (see Ben-Akiva and Lerman 1985, Ben-Akiva et al. 2002).

Challenges with the current state of literature and practice with regards to evaluation and decision making for transportation investment projects as presented in Section 1 include (1) the absence of a common framework that supports group/collective decision making within which the different stakeholders can make their decision, (2) the absence of accounting and analysis of the differences in perspectives that the different players involved on the project have, (3) the absence of a tool that promotes consultation and identifies consensus, (4) the selection of criteria and the form in which criteria are reported to the decision maker, (5) the implicit compensation across criteria which could mask the real impact of some of the important criteria and the difficulty in soliciting consistent evaluation of relative importance across criteria, and (6) the focus on criteria reflecting a deterministic state of the world. Moreover, the decision rule underlying decision makers' choices is not clear; a deterministic weighing-scoring decision making approach is assumed in most cases.

Accordingly, we propose an evaluation and decision framework that:

- $\quad$ supports group/collective decision making

- ensures transparency in the decision process 
- reflects/ describes the will of the general public (will help in efforts on "consultation") in addition to the more typically observed choices by the public and the private sectors

- identifies consensus/joint decision across the groups of stakeholders.

- incorporates different types of criteria from different analyses and represents them efficiently

- clearly communicates a project's risk return profile to the decision maker

- overcomes the "compensation effect"

- uses probabilistic decision theory

The TEBA framework is formulated as an evaluation and decision making framework in the context of transportation investment project selection. It is designed to overcome limitations identified in current frameworks within the aforementioned context. It is not an attempt to replace CBA but rather a step forward. CBA does not say how to aggregate multi-dimensional preferences. TEBA is proposed as one way to do so. Figure 3-1 displays a graphical representation of TEBA. 


\section{Phase 1: pre-analysis}

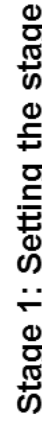

\begin{tabular}{|l|l|}
\hline $\begin{array}{l}\text { Identify need for } \\
\text { intervention }\end{array}$ \\
\hline \begin{tabular}{l} 
Develop alternatives \\
\hline Agree on procurement \\
approach
\end{tabular} \\
\hline $\begin{array}{l}\text { Identify key stakeholder } \\
\text { groups }\end{array}$ \\
\hline $\begin{array}{l}\text { Decide on criteria and } \\
\text { performance measures }\end{array}$ \\
\hline
\end{tabular}

Phase 2: Economic and Financial Appraisals

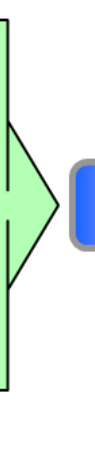

Option $i$

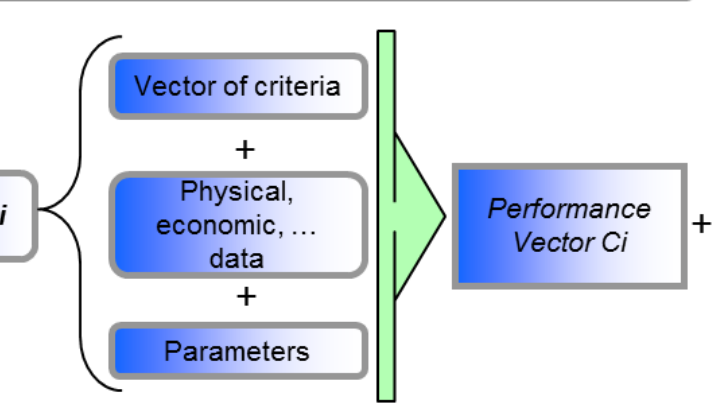

Phase 3: Decision Making - EBA by Tversky

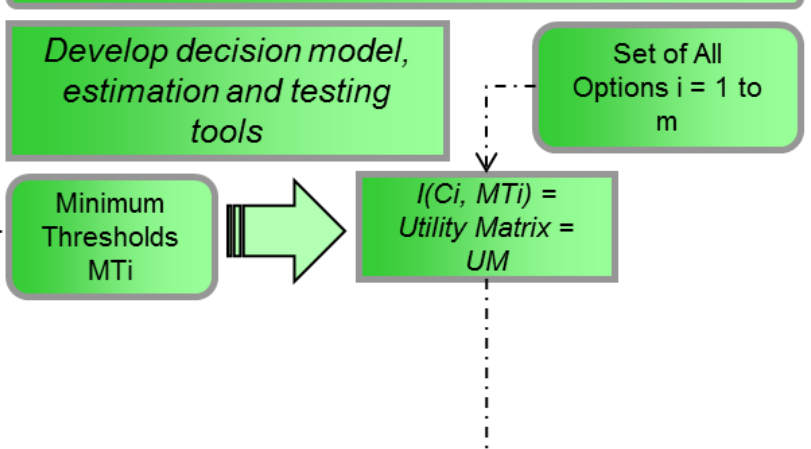

Phase 4 - Data Processing, Analysis, Model Validation, Inference making

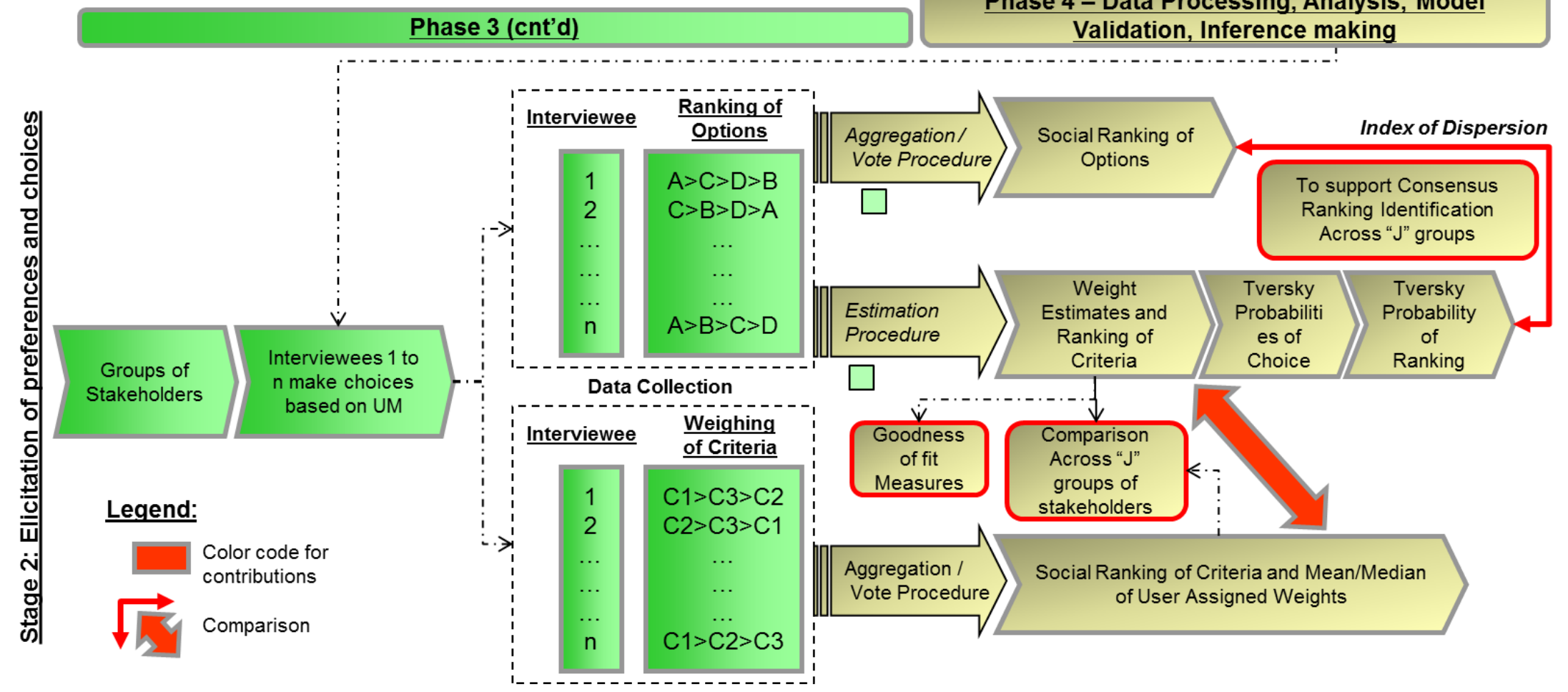

Figure 3-1 - The Transportation Elimination by Aspects Framework (TEBA) 
The TEBA framework is developed to account for perspectives of multiple key identified stakeholder groups, considered in this research to be the Public Sector, the Private Sector and the General Public groups. It considers information from both the economic and financial analyses, introduces separate risk measures, and allows analysis of group reaction to those. The framework adopts an aggregate view of decision making, by group, and generates the social deterministic ranking of options as well as the likelihood of that ranking occurring based on the probabilistic model of choice: the Elimination by aspects model (EBA). It supports consensus reaching across the three groups of stakeholders.

The first phase in the TEBA framework is pre-analysis. At this stage, the need for intervention is identified, alternatives to respond to the need are developed and the set of criteria and performance measures to describe the different options are agreed upon. These are selected based on a review of the literature to reflect a broad range of socio-economic and financial performance. The key stakeholders on the project are identified at this stage too. These are categorized into groups of decision makers that are as homogeneous as possible in terms of their stakes vis-à-vis the project at hand.

The second phase involves the economic and financial appraisals. Each option is analyzed and its performance on each of the measures identified in phase 1 is reported. Evaluation/appraisal and analysis during this stage rely heavily on concepts from CBA theory. One outcome of this stage is a main performance matrix that aggregates the results from phase 2 for all options. Also, performance submatrices are defined by selecting and reporting results for a sub-set of the criteria. The performance submatrices include three "Analysis Type"(s), namely the Economic Analysis incorporating a mix of socioeconomic and financial value measures, the Financial Analysis focused on financial value measures and the Full Analysis focused on socio-economic measures.

In the third phase utility matrices are developed based on performance sub-matrices and data is collected. Collected data includes ranking of options and weight assignment to criteria by decision makers.

The fourth phase includes the methodology to process the data, analyze the results, validate the model and make inferences. Voting procedures are used to aggregate individual rankings of options and criteria and generate the social ranking of options and criteria per group. Three voting theories/procedures (Balinski and Laraki 2007, Zahid, 2009, Young, 1988, Lippman, Nurmi) were applied:

(a) PLURALITY WINS: only considers first place winners. The number of times each option is selected in rank one is tracked. The option with most rank-one occurrences is the preferred option. 
(b) PAIRWISE WINS: every combination of two options in the choice set is identified. The preferred option (winner) in each of the resulting two-options set is tracked. The option that wins most times after considering all combinations of options ranks first. All two-option choice sets that have the rank-one option are removed. The same logic is followed with the remaining combinations of options to select rank-two option and subsequent options rankings.

(c) BORDA METHOD: associates with each option a value based on its rank. The option that scores the most is the winning option.

In case of discrepancies, the median rankings were retained. ${ }^{4}$ We refer to the ranking from this step as the “deterministic social aggregate ranking".

Individual rankings of options are used to estimate EBA utility scales and generate a Tversky probability of options' ranking. Social ranking of options and Tversky probabilities of ranking are used to validate the EBA model and support consensus ranking identification across the groups. The Index of Dispersion (ID) is developed to determine the likelihood of the deterministic social aggregate ranking and identify a consensus ranking. The Index of Dispersion, for a given sequence, is defined as the sumproduct, over all possible sequences, of the EBA probability of the tested sequence occurring and the step moves separating it from other possible sequences. Further details on the Index of Dispersion are included in Appendix A. The value of the Index of Dispersion will reflect the likelihood of the tested sequence occurring, in our case, the one corresponding to the Deterministic social aggregate Ranking (DR); a low value for the index of dispersion indicates that the sequences with highest probabilities are the ones that are "closest" to the tested sequence.

EBA estimated utility scales are compared across the groups and compared to the social ranking of criteria from direct user weight assignment. Inferences are made with respect to the validity of the model, criteria preferences by group by analysis type, options' preferences by group by analysis type, and possible consensus ranking of options.

In summary, the TEBA framework overcomes the challenges with current frameworks summarized earlier in this section as it (1) provides guidance based on synthesis of the literature for selecting group specific criteria, introduces composite criteria to explicitly account for risk, allows for large numbers of criteria to be presented to the decision maker without impacting the quality or complexity of the decision

\footnotetext{
${ }^{4}$ Example: Options A, B, C, D, E, F rank 6, 3, 5, 1, 2, 4 based on plurality wins approach, 6, 3, 4, 1, 2, 5 based on the pairwise wins approach and 6, 3, 5, 1, 2, 4 based on Borda scores, then the median ranking is $6,3,5,1,2,4$.
} 
making process and allows for criteria to be presented in their original most intuitive definitions and unit systems, (2) presents information to the decision maker in a form that does not allow implicit compensation across criteria, (3) uses voting methods alongside with EBA modeling and estimation to assess and validate the weights of the criteria, (4) includes criteria resulting from probabilistic analysis accounting for input uncertainties, (5) supports decision making by multiple stakeholder groups, (6) allows the independent analysis of the differences in perspectives on options ranking as well as criteria importance that the different players involved in the project have, and (7) defines the index of dispersion and social aggregate rankings to provide a methodology for promoting consultation and identifying consensus. Moreover, TEBA investigates and is designed to uncover the decision rule underlying decision makers' choices.

The methodology, and the underlying tools and methods are demonstrated in detail in a case study. The case study features 6 options for providing a land connection between Beirut and Damascus. It involves 3 groups of decision makers: the Public sector, the Private sector and the General public. Each group is presented with utility matrices with 7 criteria; criteria are group specific. More details are presented in the next section.

\section{TEBA Empirical Case Study}

\subsection{Demonstrating the Methodology}

Best practices from the reviewed literature on project evaluation and concepts from the TEBA framework were applied in developing the case study. The case study will reflects the four phases of TEBA.

TEBA Phase 1: Pre-Analysis; Identify need, develop alternatives, agree on procurement, identify $\underline{\text { stakeholders, and decide on decision criteria }}$

The case study deals with the land connection between Beirut and Damascus. The current road section between the two capital cities is highly congested and is frequently the scene of severe accidents. The two capitals are separated by 2 chains of mountains and are approximately $100 \mathrm{Km}$ apart. The need for an enhanced connection has long been established. ${ }^{5}$

\footnotetext{
${ }^{5}$ This research was started prior to the conflicts in Syria and the case study and surveys were conducted right before the onset of the conflicts. The analysis in the case study therefore assumes normal (not a force majeure environment) conditions governing the decision making.
} 
Technically feasible project options were developed by the authors by generating concept designs of route alignments and estimating corresponding bills of quantities. An approximation of the topographical conditions was done based on the experience of the authors with the Lebanese terrain as well as through consultation with other experts who have extensive knowledge of the region. Unofficial price quotations were obtained from active consulting firms and cost estimates were calculated accordingly. A Public Private Partnership with a BOT arrangement was identified by the authors as a preferred procurement approach to simplify the demonstration of TEBA concepts. Table 4-1 provides a summary of the options and of the rationale behind each of them:

Table 4-1 - Case study: alternative project options' description summary and rationale.

\begin{tabular}{|l|l|l|}
\hline \multicolumn{1}{|c|}{ Option description summary } & \multicolumn{1}{|c|}{ Option rationale summary } \\
\hline Option 1 & $\begin{array}{l}\text { Maintenance and rehabilitation of existing } \\
\text { highway and indirect Toll, 110 Km }\end{array}$ & Simplest intervention. \\
\hline Option 2 & $\begin{array}{l}\text { New Toll Highway, No Structures, 110 Km, } \\
\text { all weather }\end{array}$ & $\begin{array}{l}\text { Serves destinations along the route. Longer, curvier } \\
\text { alternative. Lower total cost in the absence of } \\
\text { structures and low uncertainty around the cost. }\end{array}$ \\
\hline Option 3 & $\begin{array}{l}\text { New Toll Highway, Structures Intensive, 90 } \\
\text { Km, all weather }\end{array}$ & $\begin{array}{l}\text { Supports travelers to destinations along the route. } \\
\text { Optimized alignment for quality of ride and time } \\
\text { saving. High cost and cost uncertainty. }\end{array}$ \\
\hline Option 4 & $\begin{array}{l}\text { High Speed Rail (HSR) with Minimum } \\
\text { Ktructures and No Intermediate Stops, 100 } \\
\text { Km, speed >200Km/hr }\end{array}$ & $\begin{array}{l}\text { Non-stop rapid access between the cities. Limited } \\
\text { investment in high cost structures reducing the } \\
\text { uncertainty around capital cost. }\end{array}$ \\
\hline Option 5 & $\begin{array}{l}\text { Regional Non-High Speed Rail with } \\
\text { Minimum Structures and 2 Intermediate } \\
\text { Stops, 145 Km, runs at 60 to 120 Km/hr using } \\
\text { the ROW of the existing Railway track }\end{array}$ & $\begin{array}{l}\text { Serves travelers to intermediate regions. Follows } \\
\text { existing old rail route. Low service cost. }\end{array}$ \\
\hline Option 6 & $\begin{array}{l}\text { HSR along shortest path with major structural } \\
\text { work, No Intermediate Stops, 90 Km }\end{array}$ & $\begin{array}{l}\text { The "Concorde" rail alternative. High cost of service. } \\
\text { Directed for business and point to point travelers. }\end{array}$ \\
\hline
\end{tabular}

It is generally noted that several groups of stakeholders are involved or at least concerned with the decision regarding the investment in transportation projects: investor, owner, technical actors, administrative actors, the public, non-governmental organizations, politicians and legal actors (Cundric et al. 2008, Salling and Banister 2009). Particular care should be given to the choice of the stakeholders, including a continuum of one (not treated here). For the purpose of demonstrating the TEBA methodology on this case study, we regroup stakeholders under different categories and map out as in Figure 4-1 the influence, objectives and drivers of the various groups based on a synthesis of the literature 
in Khraibani 2012. The authors then group stakeholders in 3 major groups deemed representative of the overall structure shown in Figure 4-1: the Public Sector, The Private Sector, and The General Public. The latter is to be designed in an attempt to represent "all the affected society" to the extent possible.

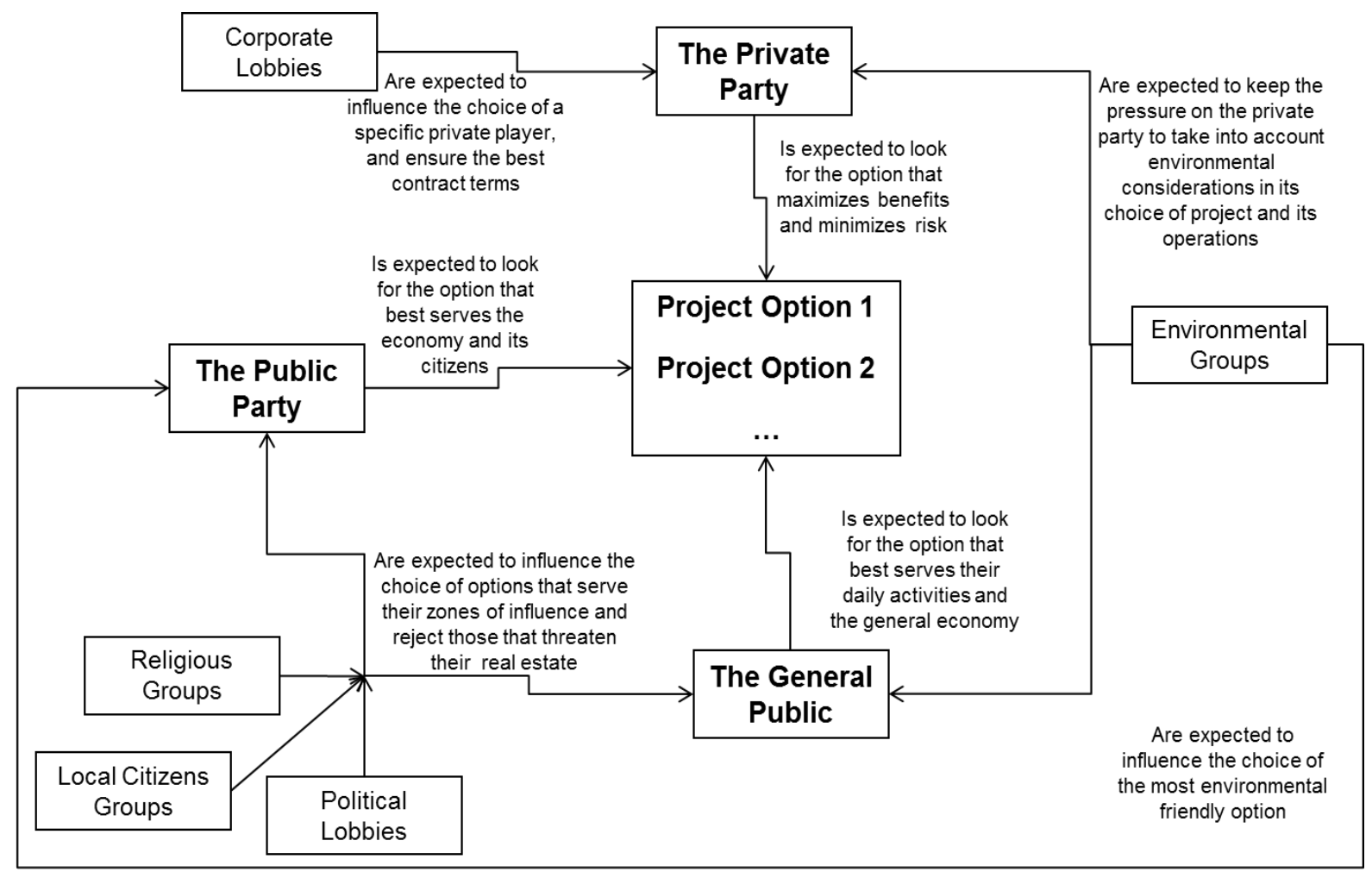

Figure 4-1 - Standpoints of different stakeholder and decision making parties - Case study: Beirut-Damascus land connection

Furthermore, 14 criteria were chosen to cover a range of socio-economic and financial value measures as well as risk measures, and were aggregated differently in 3 tables. The selection of the criteria was based on a thorough review of the literature covering various evaluation methods and most commonly used criteria. Some of the criteria are extensions to what is found in the literature, such as the combined Financial NPV and Standard deviation criterion. Some other criteria are less commonly used in the literature but are tested here to overcome what was seen as a gap in the current literature, such as the Financial NPV-at-Risk. Furthermore, a synthesis of the literature supported the choices of which criteria to present to which groups of stakeholders. For instance, while the public sector is not typically looking for financial profits especially under a BOT arrangement, it could still contemplate the financial risk/return profile to understand if the private sector partner is taking too much risk and if it expects returns that will motivate proper performance (de Palma et al. 2013). For a complete discussion of most 
commonly used criteria and the logic behind the selection of the 14 criteria for this work, the reader is referred to Khraibani 2012. Table 4-2 summarizes the list of criteria by group.

Table 4-2 - List of Criteria by Type and by Group of Respondents - Case study: Beirut-Damascus land connection

\begin{tabular}{|l|c|c|c|}
\hline \multicolumn{1}{|c|}{ List of All Criteria } & $\begin{array}{c}\text { Economic } \\
\text { Criteria } \\
\text { (communicated } \\
\text { to the Public } \\
\text { Sector) }\end{array}$ & $\begin{array}{c}\text { Financial } \\
\text { Criteria } \\
\text { (communicated } \\
\text { to the Private } \\
\text { Sector) }\end{array}$ & $\begin{array}{c}\text { Combined Set } \\
\text { of Criteria } \\
\text { (communicated } \\
\text { to all groups) }\end{array}$ \\
\hline $\begin{array}{l}\text { Expected Value of Socio-Economic NPV (benefits } \\
\text { include savings in TT, VOC, and Accidents/Deaths) }\end{array}$ & $\mathrm{X}$ & & $\mathrm{X}$ \\
\hline $\begin{array}{l}\text { Socio-Economic NPV-at-Risk (benefits include savings } \\
\text { in TT, VOC, and Accidents/Deaths) }\end{array}$ & $\mathrm{X}$ & $\mathrm{X}$ \\
\hline $\begin{array}{l}\text { Number of deaths or near-deaths causing from } \\
\text { accidents per year }\end{array}$ & $\mathrm{X}$ & $\mathrm{X}$ & $\mathrm{X}$ \\
\hline Absolute travel time on key travel segment in hours & $\mathrm{X}$ & $\mathrm{X}$ \\
\hline $\begin{array}{l}\text { Impact on Employment - Scale is 1 to 10 where 10 is } \\
\text { best }\end{array}$ & $\mathrm{X}$ & $\mathrm{X}$ & $\mathrm{X}$ \\
\hline $\begin{array}{l}\text { Impact on Accessibility of the Poorer - Scale 1 to 10 } \\
\text { where 10 is best }\end{array}$ & & $\mathrm{X}$ & $\mathrm{X}$ \\
\hline $\begin{array}{l}\text { Environmental friendliness (Including carbon } \\
\text { emissions, noise levels, cuts in forests, ...) - Scale is 1 } \\
\text { to 10 where 10 is best }\end{array}$ & & $\mathrm{X}$ & $\mathrm{X}$ \\
\hline Financial IRR Base Case Value & & $\mathrm{X}$ & \\
\hline Financial IRR Expected Value & & & \\
\hline Financial NPV Base Case Value & & & \\
\hline Financial NPV Expected Value and Standard Deviation & & & \\
\hline Financial NPV-at-Risk & & & \\
\hline $\begin{array}{l}\text { PV Initial Investments Expected Value (MT defined } \\
\text { within a range) }\end{array}$ & & & \\
\hline Payback period Expected Value & & & \\
\hline
\end{tabular}

TEBA Phase 2: Economic and Financial Appraisals; develop the performance matrix

For the case study at hand, the results of the financial and socio-economic analyses are presented in performance matrix form in Table 4-3: There is no clearly dominating option. That is, it is not readily clear that any of the six options should be chosen as a winning alternative to proceed with. 
Table 4-3 - Performance Matrix for the Case Study; Analysis by Authors - Input for the analysis compiled from publicly available information and data from experts. The parts of the table highlighed in lighter orange reflect results from the Economic Analysis while those highlighted in darker orange reflect results from the Financial Analysis as defined in Table 4-2.

\begin{tabular}{|c|c|c|c|c|c|c|c|c|c|c|c|c|c|c|c|}
\hline \multirow[b]{2}{*}{$\begin{array}{c}\text { Alternative / } \\
\text { Option }\end{array}$} & \multicolumn{15}{|c|}{ Criterion } \\
\hline & $\begin{array}{c}\text { Financial } \\
\text { IRR Base } \\
\text { Case Value } \\
\text { Value }\end{array}$ & $\begin{array}{l}\text { Financial } \\
\text { IRR } \\
\text { Expected } \\
\text { Value }\end{array}$ & $\begin{array}{c}\text { Financial } \\
\text { NPV Base } \\
\text { Case } \\
\text { Value (in } \\
\text { million \$) }\end{array}$ & $\begin{array}{r}\text { Financi } \\
\text { Expe } \\
\text { Value ( } \\
\text { (EV - S } \\
\text { Deviat } \\
\text { milli }\end{array}$ & $\begin{array}{l}\text { lal NPV: } \\
\text { ected } \\
\text { EV) and } \\
\text { tandard } \\
\text { ion) (in } \\
\text { on \$) }\end{array}$ & $\begin{array}{l}\text { Financial } \\
\text { NPV-at- } \\
\text { Risk (in } \\
\text { million \$) }\end{array}$ & $\begin{array}{l}\text { PV Initial } \\
\text { Investments } \\
\text { Expected } \\
\text { Value (MT } \\
\text { defined } \\
\text { within range) } \\
\text { (in million \$) }\end{array}$ & $\begin{array}{l}\text { Payback } \\
\text { period } \\
\text { Expected } \\
\text { Value (in } \\
\text { years) }\end{array}$ & $\begin{array}{l}\text { Expected Value } \\
\text { of Socio- } \\
\text { Economic NPV } \\
\text { (benefits } \\
\text { include savings } \\
\text { in TT, VOC, and } \\
\text { Accidents) (in } \\
\text { million \$) }\end{array}$ & $\begin{array}{l}\text { Socio-Economic } \\
\text { NPV-at-Risk } \\
\text { (benefits } \\
\text { include savings } \\
\text { in TT, VOC, and } \\
\text { Accidents) (in } \\
\text { million \$) }\end{array}$ & $\begin{array}{l}\text { Number of } \\
\text { deaths or } \\
\text { near- } \\
\text { deaths per } \\
\text { year from } \\
\text { accidents }\end{array}$ & $\begin{array}{c}\text { Absolute } \\
\text { travel time } \\
\text { on key } \\
\text { travel } \\
\text { segment in } \\
\text { hours }\end{array}$ & $\begin{array}{l}\text { Impact on } \\
\text { Employment - } \\
\text { Scale is } 1 \text { to } 10 \\
\text { where } 10 \text { is } \\
\text { best }\end{array}$ & $\begin{array}{l}\text { Impact on } \\
\text { Accessibility } \\
\text { of the Poorer - } \\
\text { Scale is } 1 \text { to } 10 \\
\text { where } 10 \text { is } \\
\text { best }\end{array}$ & $\begin{array}{c}\text { Environmental } \\
\text { friendliness } \\
\text { (Including carbon } \\
\text { emissions, noise } \\
\text { levels, cuts in } \\
\text { forests, ...) - } \\
\text { Scale is } 1 \text { to } 10 \\
\text { where } 10 \text { is best }\end{array}$ \\
\hline Option A & 10.3 & 10.5 & 2 & 2 & -6 & -12 & 61 & 11.3 & 221 & 123 & 100 & 1.4 & 1 & 1 & 1 \\
\hline Option B & 12.2 & 12.4 & 149 & 174 & -5 & -90 & 517 & 12.6 & 1,227 & 712 & 20 & 1.1 & 9 & 7 & 9 \\
\hline Option C & 10.6 & 8.4 & 93 & -222 & -557 & -790 & 1,234 & 17.5 & 1,384 & 244 & 15 & 0.9 & 7 & 6 & 6 \\
\hline Option D & 13.1 & 12.4 & 483 & 418 & -25 & -205 & 1,118 & 13.5 & 528 & 88 & 5 & 0.7 & 6 & 5 & 9 \\
\hline Option E & 12.6 & 13.6 & 314 & 517 & -19 & -150 & 878 & 12.7 & 3,599 & 2,036 & 5 & 1.4 & 7 & 9 & 7 \\
\hline Option F & 15.1 & 12.3 & 900 & 474 & -302 & -641 & 1,322 & 14.4 & 384 & -397 & 5 & 0.5 & 9 & 4 & 6 \\
\hline
\end{tabular}


From the global performance matrix we define three subset performance matrices regrouping the criteria as described in the top row of Table 4-2. The first performance matrix includes only the socio-economic criteria (PM1), the second includes only the financial criteria (PM2) and the third includes a combination of those (PM3).

TEBA Phase 3: EBA Decision Making; Setting Minimum Thresholds, developing Utility Matrices, conducting interviews, collecting ranking data for options and criteria

Then, EBA was adopted as the decision model and MT vectors were defined corresponding to each performance matrix. Some criteria such as "Financial NPV Expected Value and Standard Deviation" are composite criteria and two thresholds, also assigned by experts, were used accordingly. Double bound thresholds for some other criteria such as "PV Initial Investments Expected Value (MT defined within range)" were used.

The resulting utility matrix was generated for each performance matrix. Table 4-4 shows the Economic Utility Matrix, UM1 resulting from MT1 and PM1.

Table 4-4 - Utility Matrix UM1, Economic Analysis

\begin{tabular}{|c|c|c|c|c|c|c|c|}
\hline \multirow[b]{2}{*}{$\begin{array}{c}\text { Alternative } \\
\text { /Option }\end{array}$} & \multicolumn{7}{|c|}{ Criterion } \\
\hline & $\begin{array}{l}\text { Expected Value of } \\
\text { Socio-Economic NPV } \\
\text { (in million \$) }\end{array}$ & $\begin{array}{c}\text { Socio-Economic NPV- } \\
\text { at-Risk } \\
\text { (in million \$) }\end{array}$ & $\begin{array}{l}\text { - Number of deaths or } \\
\text { near-deaths per year } \\
\text { from accidents }\end{array}$ & $\begin{array}{c}\text { Absolute travel time } \\
\text { on key travel } \\
\text { segment in hours }\end{array}$ & $\begin{array}{c}\text { Impact on } \\
\text { Employment } \\
\text { Scale } 1 \text { to } 10 ; 10 \text { is } \\
\text { best }\end{array}$ & $\begin{array}{c}\text { Impact on } \\
\text { Accessibility of the } \\
\text { Poorer } \\
\text { Scale } 1 \text { to } 10 ; 10 \text { is } \\
\text { best }\end{array}$ & $\begin{array}{l}\text { Environmental } \\
\text { friendliness } \\
\text { Scale } 1 \text { to } 10 ; 10 \text { is } \\
\text { best }\end{array}$ \\
\hline MT1 & 500 & 100 & 10 & 1 & 9 & 9 & 9 \\
\hline Option A & 0 & 1 & 0 & 0 & 0 & 0 & 0 \\
\hline Option B & 1 & 1 & 0 & 0 & 1 & 0 & 1 \\
\hline Option C & 1 & 1 & 0 & 1 & 0 & 0 & 0 \\
\hline Option D & 1 & 0 & 1 & 1 & 0 & 0 & 1 \\
\hline Option E & 1 & 1 & 1 & 0 & 0 & 1 & 0 \\
\hline Option F & 0 & 0 & 1 & 1 & 1 & 0 & 0 \\
\hline
\end{tabular}

UM1 was used by the decision makers in the Public Sector sub-group to make choices on preferred alternatives. Similarly, utility matrices for the other sub-groups were generated from a distinct grouping of the criteria. The utility matrices were communicated to the decision makers through an online survey. 
All options were presented at first in the survey. The interviewee was then asked to make a choice of a preferred option among the available options. Once a choice is made, that option was removed from the set of available options and the utilities matrix now had one less option. The interviewee was asked to choose a preferred option from the updated reduced set of options. This was repeated until all options were exhausted. This same process was conducted for the different utility matrix types, i.e. this same process was applied with the interviewee being presented (separately) with the financial utility matrix, the economical utility matrix and the combination/general utility matrix. This represented one ranking event for a given utility matrix type. Afterwards, the interviewee was given the chance to provide his own set of MT values. Finally, the interviewee was asked to assign a weight to characteristics on a scale from 1 to 10. This concluded the survey and information from this last section was used to calibrate model results.

\section{TEBA Phase 4: Data processing and analysis, model validation, inference making}

Voting theory principles were employed to conduct a deterministic analysis of the responses of interviewees with respect to alternatives and criteria as described in Section 3.

The deterministic social aggregate ranking of options is generated accordingly. For each group and each corresponding relevant analysis type, assuming no heterogeneity within the group, EBA was investigated as a probabilistic model of choice governing the selection and ranking of preferred options. The value of the Index of Dispersion (ID) reflects the likelihood of the tested sequence occurring, in our case, the one corresponding to the Deterministic social aggregate Ranking (DR). The case for the Public Sector responding to the Economic Analysis DT1 is presented for illustrative purposes. The distribution of the IDs for all sequences is presented in Figure 4-2. A beta distribution fits the data with an acceptable A-D (Anderson-Darling) coefficient of 0.091. 


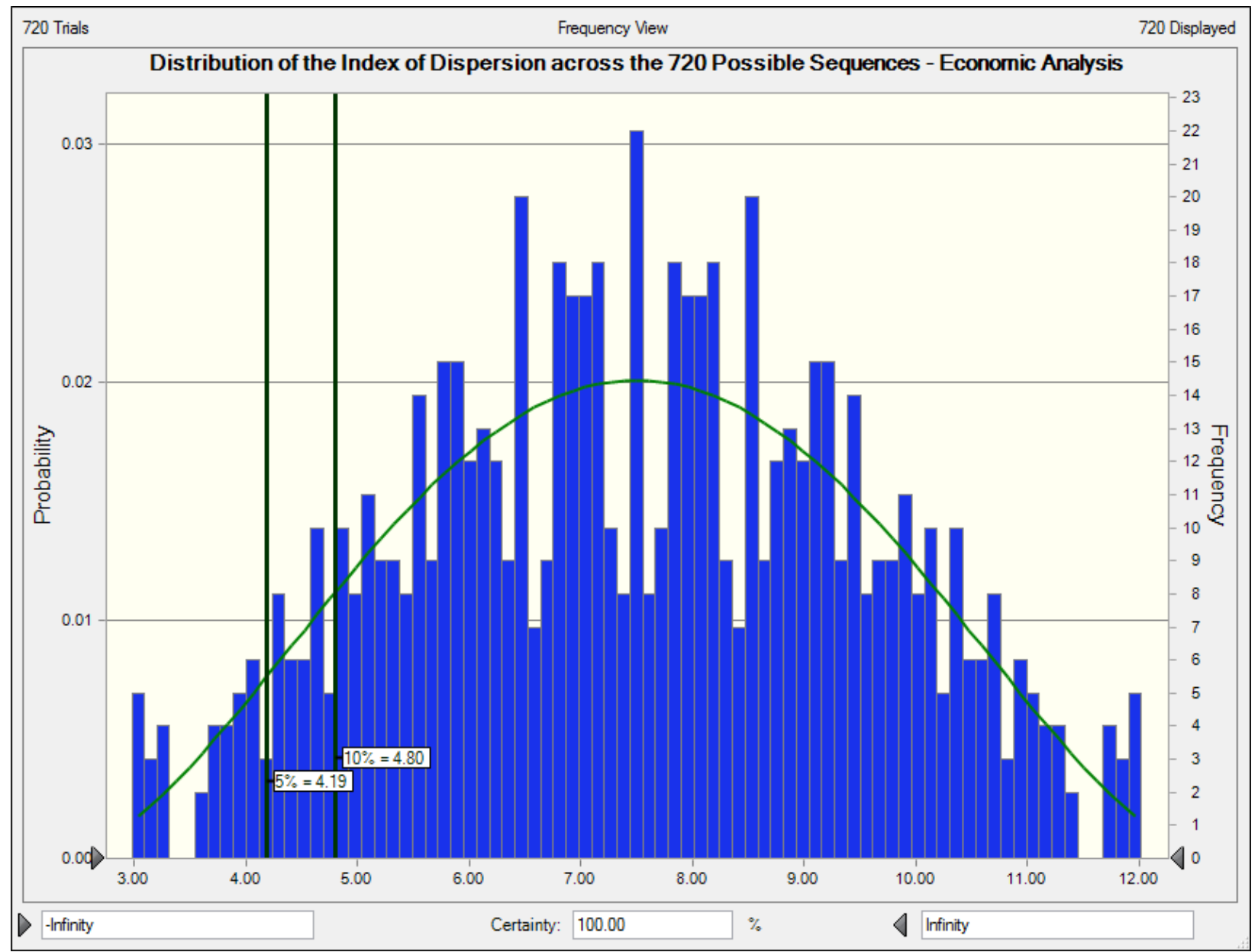

Figure 4-2 - Distribution of the Index of Dispersion across all Possible Sequences for Results from the Economic Analysis

The $5^{\text {th }}$ percentile value from the distribution shown above is 4.19 . It follows that sequences with an index of dispersion lower than 4.19 have a 95 percent likelihood of being generated by the model. The $5^{\text {th }}$ percentile value is referred to as the Cut-off point. Models that return an Index of Dispersion for the social deterministic aggregate ranking below the cut-off point are validated.

For the illustrative case of the Public Sector responding to the Economic Analysis in the case study, Table 4-5 presents the sequence generated from the social deterministic aggregated ranking and the corresponding calculated probability and Index of Dispersion.

Table 4-5 - Index of Dispersion for Aggregated Social Rankings

\begin{tabular}{|r|c|c|c|c|c|c|}
\hline & Rank 1 & Rank 2 & Rank 3 & Rank 4 & Rank 5 & Rank 6 \\
\hline Median Ranking from Aggregation Methods & D & E & B & F & C & A \\
\hline Index of Dispersion & 3.03 &
\end{tabular}


'With an index of dispersion of 3.03, it is highly likely (more than 95\% chance) that the EBA model will reproduce the social deterministic aggregate ranking generated using standard voting theory. This validates the fit of the EBA model in this application.

A consensus ranking is identified by determining the sequence of options that has the lowest "joint likelihood". In other words, the sequence that has an ID below the cut-off ID for the three stakeholder groups, if it exists, is designated as the consensus sequence.

\subsection{Results and Key Insights}

\section{$\underline{\text { Options results }}$}

The deterministic social aggregate rankings (the median ranking from the application of the three voting theory rules described earlier) that resulted from each of the groups/decision table combinations are distinct as presented in Table 4-6.

Table 4-6 - Deterministic Social Aggregated Rankings by Group and Analysis Type

\begin{tabular}{|c|c|c|c|c|c|c|c|}
\hline \multirow{2}{*}{ Group } & Analysis & \multicolumn{7}{|c|}{ Option Ranking } \\
\cline { 3 - 9 } & & Option A & Option B & Option C & Option D & Option E & Option F \\
\hline Public & Eco & 6 & 3 & 4 & 1 & 2 & 5 \\
\hline Private & Fin & 5 & 2 & 6 & 3 & 1 & 4 \\
\hline General & Full & 6 & 3 & 5 & 2 & 4 & 1 \\
\hline ALL & Full & 6 & 3 & 5 & 1 & 2 & 4 \\
\hline Public & Full & 5 & 2 & 4 & 3 & 1 & 6 \\
\hline Private & Full & 3 & 4 & 6 & 1 & 2 & 5 \\
\hline
\end{tabular}

Based on both deterministic results, groups will rank options differently when provided with different or identical sets of criteria, confirming the need for noting the 3 perspectives and identifying a consensus mechanism.

The results from testing the EBA model under no heterogeneity assumptions for the deterministic social aggregate ranking by group are presented in Table 4-7 . 
Table 4-7 - Summary of EBA Models Testing Results, by Group and Analysis Type

\begin{tabular}{|c|c|c|c|c|c|c|}
\hline \multirow[b]{2}{*}{ Group } & \multirow[b]{2}{*}{ Analysis Type } & \multirow[b]{2}{*}{ chi-square } & \multirow[b]{2}{*}{ p-value } & \multicolumn{2}{|c|}{ Index of Dispersion } & \multirow[b]{2}{*}{ EBA is: } \\
\hline & & & & $\begin{array}{c}\text { Cut-off @ 5th } \\
\text { percentile }\end{array}$ & Ranking ID & \\
\hline Public & Eco & 4.8 & $>0.1$ & 4.2 & 3.03 & Accepted \\
\hline Private & Fin & 8.6 & $>0.1$ & 4.2 & 2.93 & Accepted \\
\hline General & Full & 3.48 & $>0.1$ & 6.8 & 6.82 & Accepted \\
\hline
\end{tabular}

Statistical tests, including (1) p-values > 0.1 and (2) Indices of Dispersion for a group's winning ranking below the cut-off Index of Dispersion for that group, indicate that it is highly likely that stakeholders have employed EBA in making decisions.

\section{Consensus Analysis}

Based on the social deterministic aggregated rankings by the 3 groups of stakeholders making decisions based on group specific analyses, as reported in Table 4-1, a sequence of options that is representative of the preferences of all three groups could not be identified. For all three groups making decisions based on group specific analysis, an EBA model was provided, accepted, and validated. Accordingly, the index of dispersion for any sequence can be identified from each of the resulting 3 EBA models. As noted earlier, rankings that return an index of dispersion below a pre-defined cut-off point for a given EBA model have a high likelihood and are therefore rankings that are highly likely to be a preferred outcome of the model. The ranking that has IDs lower than the cut-off point for the EBA models of the 3 groups of stakeholders and that has the lowest sum of the IDs across the three groups is considered the consensus sequence. Table 4-8 displays the ranking identified as the consensus ranking as well as information on the ranking generated from applying the Borda rule to the three deterministic rankings from Table 4-6. The latter has one of the lowest sum of ID's but does not meet the $5^{\text {th }}$ percentile ID cut-off limit for both the Private Sector and the General Public. While the consensus ranking has a slightly larger sum, it does meet the $5^{\text {th }}$ percentile ID cut-off for all three groups. Also, the sum of ID's is in the top 1.5\% of sums of IDs across all 720 ranking combinations.

The consensus ranking identified based on the EBA analysis is therefore one that is highly likely to reflect/satisfy the choices/preferences of all three groups. 
Table 4-8 - Testing the proposed synthesized sequence from deterministic aggregation

\begin{tabular}{|c|c|c|c|c|c|c|c|}
\hline Selected Rankings & $\begin{array}{l}\text { ID } \\
\text { Eco }\end{array}$ & ID Fin & $\begin{array}{l}\text { ID } \\
\text { Full }\end{array}$ & $\begin{array}{l}\text { Meets ID } \\
\text { Cut-off for } \\
\text { Eco }=4.2 \\
\quad @ 5 \% ?\end{array}$ & $\begin{array}{l}\text { Meets ID } \\
\text { Cut-off for } \\
\text { Fin }=4.2 \\
\quad @ 5 \% \text { ? }\end{array}$ & $\begin{array}{l}\text { Meets ID } \\
\text { Cut-off for } \\
\text { Full }=6.8 \\
\quad \text { @ } 5 \% \text { ? }\end{array}$ & $\begin{array}{l}\text { Sum } \\
\text { of } \\
\text { IDs }\end{array}$ \\
\hline $\mathrm{D}>\mathrm{E}>\mathrm{B}>\mathrm{F}>\mathrm{C}>\mathrm{A}^{*}$ & 3.0 & 4.6 & 6.9 & Yes & No & No & 14.51 \\
\hline $\mathbf{D}>\mathbf{B}>\mathbf{E}>\mathbf{F}>\mathbf{A}>\mathbf{C} * *$ & 4.0 & 4.0 & 6.7 & Yes & Yes & Yes & 14.70 \\
\hline \multicolumn{8}{|c|}{$\begin{array}{l}\text { * Ranking generated from using Borda rule to deterministic rankings by three groups (refer to Table 4-6) } \\
\text { ** Ranking with lowest sum of IDs (1.5th percentile) while meeting 5th percentile ID cut-off for all three } \\
\text { groups }\end{array}$} \\
\hline
\end{tabular}

\section{Criteria Results - Weights Analysis}

The respondents in each group assigned weights to criteria from relevant analyses. Those weights reflect the importance of each criterion on a scale from 1 to 10 . The medians of those weights by group by analysis type are presented in Table 4-9.

For the three combinations of groups and analysis types for which the EBA model was found to be highly significant, the parameters of the EBA models by group by analysis type are presented in Table 4-9. Those parameters are the EBA utility scales described in Section 2.

Deterministic weight assignment seems to attenuate the difference in weights across the criteria, especially for the Public Group. For instance, averages of weights assigned by the Public Sector to the seven criteria in the Economic Analysis span the narrow range of 0.78 to 1 with an average of 0.88 and a standard deviation of 0.09 .

EBA weights distribution suggests that only 3 to 4 criteria are key to reaching a decision. For instance, for the Public Sector making decisions based on the Economic Analysis and the Private Sector making decisions based on the Financial Analysis, weights/utility scales estimated from the EBA model of each combination reveal that there is an $84 \%$ and $82 \%$ chance, respectively, that the top 3 criteria would be selected as criteria for elimination. In other words, in more than $80 \%$ of the cases, the elimination of options will be conducted based on the top three criteria. 
Table 4-9 - Weights of Criteria based on Deterministic Aggregation vs EBA Estimation

\begin{tabular}{|c|c|c|c|c|c|c|c|c|c|c|}
\hline \multicolumn{8}{|c|}{ Median of Deterministic Assigned Weights and Point Estimate from EBA Model } & $\begin{array}{c}\text { Mean Across } \\
\text { Criteria Det. } \\
\text { Weights }\end{array}$ & $\begin{array}{c}\text { Strd. Dev. } \\
\text { Across Cr. } \\
\text { Det. Weights }\end{array}$ & $\begin{array}{c}\text { Prob. of } \\
\text { Select. of } \\
\text { Top } 3 \\
\text { Criteria }\end{array}$ \\
\hline \multicolumn{11}{|c|}{ Public - Eco } \\
\hline Criterion & $\mathrm{E}(\mathrm{ENPV})$ & ENPV-at-Risk & $\begin{array}{c}\text { Nb of deaths } \\
\text { or near- } \\
\text { deaths }\end{array}$ & $\begin{array}{l}\text { Absolute } \\
\text { travel time }\end{array}$ & $\begin{array}{l}\text { Impact on } \\
\text { Employment }\end{array}$ & $\begin{array}{l}\text { Impact on } \\
\text { Accessibility } \\
\text { of the Poorer }\end{array}$ & $\begin{array}{l}\text { Environmenta } \\
\text { I friendliness }\end{array}$ & & & \\
\hline Assigned & 1.00 & 0.78 & 0.88 & 0.79 & 1.00 & 0.88 & 0.83 & 0.88 & 0.09 & \\
\hline EBA & 1.00 & 0.15 & 0.40 & 0.08 & 0.21 & 0.00 & 0.09 & & & $84 \%$ \\
\hline \multicolumn{11}{|c|}{ Private - Fin } \\
\hline Criterion & $\begin{array}{c}\text { Financial IRR } \\
\text { Base Case } \\
\text { Value Value }\end{array}$ & $\begin{array}{c}\text { Financial IRR } \\
\text { Expected } \\
\text { Value }\end{array}$ & $\begin{array}{c}\text { Financial NPV } \\
\text { Base Case } \\
\text { Value }\end{array}$ & $\begin{array}{c}\text { Financial } \\
\text { NPV: (EV) } \\
\text { and (EV - SD) }\end{array}$ & $\begin{array}{c}\text { Financial NPV } \\
\text { at-Risk }\end{array}$ & $\begin{array}{c}\text { PV Initial } \\
\text { Investments } \\
\text { Expected } \\
\text { Value } \\
\end{array}$ & $\begin{array}{l}\text { Payback } \\
\text { period } \\
\text { Expected } \\
\text { Value }\end{array}$ & & & \\
\hline Assigned & 1.00 & 1.33 & 1.00 & 1.67 & 1.17 & 1.00 & 1.00 & 1.17 & 0.25 & \\
\hline EBA & 1.00 & 0.62 & 0.35 & 2.98 & 0.39 & 0.00 & 0.24 & & & $82 \%$ \\
\hline \multicolumn{11}{|c|}{ General - Full } \\
\hline Criterion & $\begin{array}{c}\text { Financial } \\
\text { NPV: (EV) } \\
\text { and (EV - SD) }\end{array}$ & $\begin{array}{c}\text { Financial NPV } \\
\text { at-Risk }\end{array}$ & $\begin{array}{l}\text { Payback } \\
\text { period } \\
\text { Expected } \\
\text { Value } \\
\end{array}$ & $\begin{array}{c}\text { EV of Socio- } \\
\text { Economic } \\
\text { NPV }\end{array}$ & $\begin{array}{c}\text { Socio- } \\
\text { Economic } \\
\text { NPV-at-Risk }\end{array}$ & $\begin{array}{l}\text { Absolute } \\
\text { travel time }\end{array}$ & $\begin{array}{c}\text { Impact on } \\
\text { Employment }\end{array}$ & & & \\
\hline Assigned & 1.00 & 1.20 & 1.33 & 1.63 & 1.75 & 2.00 & 2.42 & 1.62 & 0.49 & \\
\hline EBA & 1.00 & 0.04 & 0.97 & 0.44 & 0.56 & 1.46 & 0.80 & & & $65 \%$ \\
\hline
\end{tabular}

\section{Criteria Results - Ranking Analysis}

The results of ranking of criteria resulting from the two approaches are then investigated. Consistency in criteria ranking was generally acceptable. These results are presented in Table 4-10. Cells shown in similar colors indicate ranking positions that were close to tie.

Consistency across deterministic and EBA estimated rankings of criteria is noted for top 2 to 3 criteria. Also, the ranking of top criteria across groups is consistent with what the authors expected based on the literature review. The public sector ranks the expected value of the socio-economic NPV at the top. The private sector ranks first the financial NPV expected value and (expected value - standard deviation). The general public cares most about travel time. 
Table 4-10 - Ranking of Criteria based on Deterministic Social Aggregation vs Ranking of Criteria from EBA Weights Estimation

\begin{tabular}{|c|c|c|c|c|c|c|c|c|}
\hline \multicolumn{8}{|c|}{$\begin{array}{c}\text { Criteria Ranking (criteria with same highlight color refer to criteria that were in tight } \\
\text { competition for a rank) }\end{array}$} & \multirow[t]{3}{*}{$\begin{array}{l}\text { Consistency of Criteria } \\
\text { Importance Ranking }\end{array}$} \\
\hline \multicolumn{8}{|c|}{ Public - Eco } & \\
\hline Criterion & E(ENPV) & ENPV-at-Risk & $\begin{array}{c}\mathrm{Nb} \text { of deaths } \\
\text { or near- } \\
\text { deaths }\end{array}$ & $\begin{array}{l}\text { Absolute } \\
\text { travel time }\end{array}$ & $\begin{array}{l}\text { Impact on } \\
\text { Employment }\end{array}$ & $\begin{array}{c}\text { Impact on } \\
\text { Accessibility } \\
\text { of the Poorer }\end{array}$ & $\begin{array}{c}\text { Environmenta } \\
\text { I friendliness }\end{array}$ & \\
\hline Assigned & 1 & 7 & 2 & 6 & 3 & 4 & 5 & \multirow{2}{*}{ Acceptable } \\
\hline EBA & 1 & 5 & 2 & 6 & 3 & 7 & 4 & \\
\hline \multicolumn{9}{|c|}{ Private - Fin } \\
\hline Criterion & $\begin{array}{l}\text { Financial IRR } \\
\text { Base Case } \\
\text { Value Value }\end{array}$ & $\begin{array}{l}\text { Financial IRR } \\
\text { Expected } \\
\text { Value }\end{array}$ & $\begin{array}{c}\text { Financial NPV } \\
\text { Base Case } \\
\text { Value }\end{array}$ & $\begin{array}{c}\text { Financial } \\
\text { NPV: (EV) } \\
\text { and (EV - SD) }\end{array}$ & $\begin{array}{c}\text { Financial NPV } \\
\text { at-Risk }\end{array}$ & $\begin{array}{c}\text { PV Initial } \\
\text { Investments } \\
\text { Expected } \\
\text { Value } \\
\end{array}$ & $\begin{array}{l}\text { Payback } \\
\text { period } \\
\text { Expected } \\
\text { Value }\end{array}$ & \\
\hline Assigned & 6 & 2 & 5 & 1 & 3 & 4 & 7 & \multirow{2}{*}{ Acceptable } \\
\hline EBA & 3 & 2 & 4 & 1 & 5 & 7 & 6 & \\
\hline \multicolumn{9}{|c|}{ General - Full } \\
\hline Criterion & $\begin{array}{c}\text { Financial } \\
\text { NPV: (EV) } \\
\text { and (EV - SD) }\end{array}$ & $\begin{array}{c}\text { Financial NPV } \\
\text { at-Risk }\end{array}$ & $\begin{array}{l}\text { Payback } \\
\text { period } \\
\text { Expected } \\
\text { Value }\end{array}$ & $\begin{array}{l}\text { EV of Socio- } \\
\text { Economic } \\
\text { NPV }\end{array}$ & $\begin{array}{c}\text { Socio- } \\
\text { Economic } \\
\text { NPV-at-Risk }\end{array}$ & $\begin{array}{l}\text { Absolute } \\
\text { travel time }\end{array}$ & $\begin{array}{l}\text { Impact on } \\
\text { Employment }\end{array}$ & \\
\hline Assigned & 4 & 5 & 7 & 3 & 6 & 1 & 2 & \multirow{2}{*}{$\begin{array}{c}\text { Acceptable for top } \\
\text { criteria }\end{array}$} \\
\hline EBA & 2 & 7 & 3 & 5 & 6 & 1 & 4 & \\
\hline
\end{tabular}

Minimum Thresholds Analysis

Figure 4-3 presents the MT distributions for all 3 groups for criteria in the Full Analysis.

Plots of the minimum threshold (MT) values input by the decision makers reveal an increasing risk perception with increasing criterion importance. For instance, the private sector's distribution of MTs for the Financial NPV EV is most shifted to the right while the Payback period for that same group is most shifted to the left. The private sector puts higher constraints on these 2 profit driving criteria. The general public is clearly on the opposite side with MTs reflecting lower financial expectations from the project. 

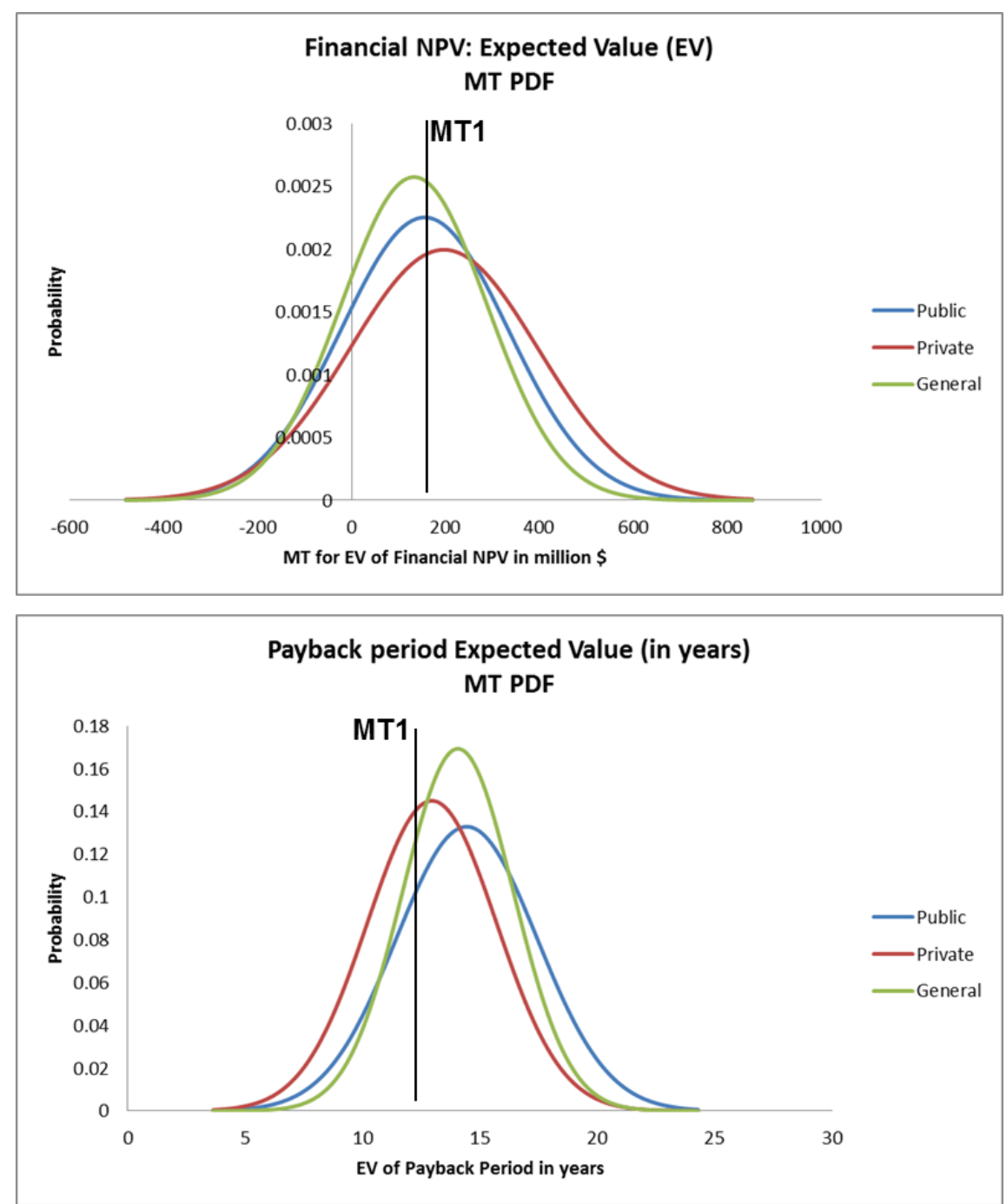

Figure 4-3 - MT Probability Distribution Functions for Criteria in Full Analysis Matrix, based on values assigned by the 3 stakeholder groups

\subsection{Discussion of Results and Key Insights}

The EBA model does explain the choices made by groups in the context defined in this work. It also supports the identification of a sequence of options with highest likelihood across the three groups resulting in a "consensus" sequence.

As expected, even when faced with the same set of information (the Full Analysis), groups' choices of options are not the same.

The MT values assigned by the three groups to criteria in the Full Analysis revealed an increasing risk aversion with increasing importance of the criterion. It also revealed a tendency to be more "demanding", 
or stringent, with respect to criteria that matter most, with the group that cares most about a criterion assigning the most constraining minimum threshold value.

Averaging of absolute values of weights assigned by users yielded unsatisfactory results. This is a result of "attenuation effect" from averaging weights across the responses of the groups' members. In the particular case of the Public Sector, this was further traced back to a biased tendency on the side of the interviewee to a concentrated use of the 5 to 10 range of the 1 to 10 scale. On the other hand, the rankings of criteria resulting from the weights assignment yielded results significantly in-line with expectations. We therefore adopt ranking comparison of criteria rather than weights comparison.

It is interesting to note that both the public sector and the general public had a similar particular interest in the criterion Impact on Employment. In fact, results from the deterministic analysis and from the EBA model estimation indicate that the most important criterion to each of the groups was exactly as expected and discussed in the literature and in practice. The private sector cares first and foremost about financial value and risk, the public sector first looked into economic value and risk while the first concern for the general public was travel time.

For further details on survey results and analysis the reader is referred to Khraibani 2012.

\subsection{Survey Notes}

The interviewees were also requested to make an explicit statement at the end of the survey describing the approach they followed while making choices on preferred options along the survey steps. Amongst those who replied, not surprisingly, a group mentioned a compensatory approach similar to a basic linear additive approach, basically favoring the options whose total score based on addition of criteria weights was highest. On the other hand, another group outlined a non-compensatory lexicographic approach whereby options that did not meet their most important criteria were eliminated sequentially. There was therefore a veto component to their decision. The hypothesis that the EBA model can explain the decision process governing the choices made within the TEBA framework is therefore worth further investigation.

For more details about the survey, including more information on the web-survey steps, the architecture of the data input from the web-survey, survey timeline, choice of target groups/respondents, and distribution of respondents, data processing and estimation platform, the reader is referred to Appendix B. 


\section{TEBA for Policy Making}

This work presented a new evaluation and decision making framework (and methodology) for large transportation projects to elicit, structure and quantify the aggregation of the preferences over project alternatives of three types of stakeholders, the TEBA framework. It tested and validated the proposed framework using a case study designed for this purpose and communicated to stakeholders through an interactive online survey. This paper also demonstrated the use of the TEBA framework as a tool to reach consensus on projects' ranking by identifying the ranking with highest likelihood across all stakeholder groups, given that the likelihoods are significant. In addition, this paper demonstrated the use of an individual decision model, EBA, for group decision making. It also demonstrated the use of a noncompensatory choice model for transportation infrastructure investment decisions. The use of combined criteria and two sided thresholds in the context of EBA is another contribution.

More specifically, the TEBA framework was shown to overcome the challenges laid out in Section 3 as it (1) supported group/collective decision making, (2) used deterministic voting methods alongside with EBA modeling and estimation to assess and validate the weights of the criteria, (3) was validated as a framework for multiple stakeholder groups and allowed the independent analysis of the differences in perspectives on options ranking as well as criteria importance that the different players involved on the project had, including the General Public, (4) defined the index of dispersion and social aggregate rankings to provide a methodology for promoting concentration and identifying consensus, (5) provided guidance based on synthesis of the literature for selecting group specific criteria, introduced composite criteria to explicitly account for risk, allowed for large numbers of criteria to be presented to the decision maker without impacting the quality or complexity of the decision making process and allowed for criteria to be presented in their original most intuitive definitions and unit systems, and (6) presented information to the decision maker in a form that does not allow implicit compensation across criteria while focusing on criteria resulting from probabilistic analysis accounting for input uncertainties. Moreover, TEBA investigated and successfully uncovered using econometric methods the decision rule underlying decision makers' choices to be a probabilistic non-compensatory model of choice.

Key results from the case study showed that it is highly likely that stakeholders have employed EBA in making decisions. Results also highlighted distinct rankings of options by the different stakeholder groups; the EBA model supported identification of a consensus ranking of options. Results also suggest that the most important criterion for every group based on EBA utility estimates was consistent with the expectations based on the literature review and the EBA analysis suggested that only the top 3 to 4 criteria are significant in reaching a decision. Furthermore, aggregation of deterministic user assigned weights 
attenuated differences across criteria for some of the groups and analysis of user assigned weights. MT values suggested higher risk perception with increased criterion importance.

Policy implications are generated accordingly. It is recommended to reach out to key stakeholders and request their direct input on decision making in the aforementioned context and reduce the role of "experts" in decision making. The role of experts should be limited to the performance appraisal stage and to setting Minimum Thresholds where applicable. Minimum threshold values should be cross checked with distributions of MTs solicited from the various decision makers. MT vectors should be tailored for each group. Also, the decision making should be modeled in a probabilistic framework rather than a deterministic "one score" approach. The project owners should seek to identify a consensus ranking of available options that reflects the preferences of the key stakeholder groups involved in the process. This is a ranking that is likely enough to result from each group's choices. Moreover, particular attention should be placed on determining the values of the criteria that emerged as "top" at the evaluation stage. Along the same lines, it appears that there is preliminary evidence that "expected values" of performance measures have higher worth than base case values to decision makers. Also, risk measures proved important to decision making by the Private sector. Decision makers should refrain from direct assignment of relative weights and an increase in awareness with respect to the importance of these measures for the Public Sector and General Public groups is recommended. In particular, the Value-atRisk measures should be included in the set of key criteria as an effective measure of risk.

At the framework formulation level, it should be noted that the three groups investigated are not necessarily extensive. The set of criteria that was investigated was based on a thorough analysis of the literature but is not extensive either. Moreover, the information made available in the decision tables of the TEBA framework does not guarantee the selection of the "optimal" option. This is related to the fact that the decision tables only indicate a one-bounded MT in general EBA models. It is believed that this may be remedied by indicating two sided MTs. An example on this was the use of a lower bound and an upper bound for the PV Initial Investments Expected Value referred to as EV(PVinvest) criterion; only options that had an EV(PVinvest) that falls between the two boundary values were reflected with a 1 in the utility matrix.

With respect to the case study, it should be noted that it treated the case of a project in Lebanon, a third world country, and a large proportion of the stakeholders were from Lebanon. Also, the case study featured strictly land transportation options. Moreover, it did not account for the effect of freight transportation. Also, the sample size was limited but produced statistically significant results. The 
framework and the approach were tested for the first time in this work. Accordingly, further testing and applications are required and results are not readily generalizable at this stage.

The key direction for extending this research is to investigate a compensatory discrete choice model in a context similar to the one described in this work. Comparing the results of this proposed analysis to the ones concluded from this work can be undertaken. One other possible line of research to extend along is the groups of stakeholders we investigate.

This research benefitted from the financial support of ANR project ELITISME, as well as LABEX Labex MME-DII.

\section{$\underline{\text { Acknowledgements }}$}

The authors would like to thank Emile Quinet and Stef Proost for valuable feedback on the original work. The authors would also like to thank all those who supported the development of the survey tools and deployment. Special appreciation goes to the professional women and men who took the time to complete the survey and provided us with the database that made this work possible.

\section{$\underline{\text { References }}$}

Adler H.A, Economic Appraisal of Transport Projects: a manual with Case studies. Baltimore: John Hopkins University Press, 1987

Anderson S., de Palma A., and Thisse J.F, Discrete Choice Theory of Product Differentiation. Cambridge, Massachusetts: The MIT Press, 1992

Balinski M. and Laraki R., A theory of measuring, electing and ranking, PNAS, 2007, vol. 104, nb. 21, pp. $8720-8725$

Ben-Akiva M. and Lerman S., Discrete Choice Analysis: Theory and Application to Travel Demand. Cambridge, Massachusetts: The MIT Press, 1985

Ben-Akiva M., McFadden D., Train K., Walker J., Bhat C., Bierlaire M., Bolduc D., Boersch-Supan A., Brownstone D., Bunch D., Daly A., de Palma A., Gopinath D., Karlstrom A. and Munizaga M., Hybrid Choice Models: Progress and Challenges, Marketing Letters, 2002, 13:3, pp. 163-175

Berechman J., The evaluation of transportation investment projects. New York: Routledge, 2009

Bristow A.L. and Nellthorp J., Transport Project Appraisal in the European Union, Transport Policy, 2000, vol. 7, pp. 51-60

Cundric A., Kern T. and Rajkovic V., A qualitative model for road investment appraisal, Transport Policy, 2008, vol. 15, pp. 225-231 
de Palma A., Lindsey R. and Proost S. (eds.), Investment and the Use of Tax and Toll Revenues in the Transport Sector, Elsevier Science, 2007.

de Palma A., Picard N., Andrieu L., Risk in Transport Investments, Networks and Spatial Economics, 2009, pp. 1-18

de Palma A., Picard N., and Ziegelmeyer A., Individual and couple decision behavior under risk : evidence on the dynamics of power balance, Theory and Decision, 2011, vol. 70-1, pp. 45-64.

de Palma A., R. Lindsey, E. Quinet \& R. Vickerman (eds.), Handbook in Transport Economics, Edgar Elgard, 2013

de Palma A. and Kilani K., Working Paper <hal-00690299>, Lower-order logsums, 2015

DTLR, DTLR multi-criteria analysis manual, prepared by a team from NERA (National Economic Research Associates) consisting of Doddgson et al.

Fader P.S. and McAlister L., An elimination by aspects model of consumer response to promotion calibrated on UPS scanner data, Journal of Marketing Research, August 1990, vol. XXVII, pp. 322-332

Gati I. and Fassa N., Applying decision theory to career counseling practice: The sequential elimination approach, March 1995, Career Development Quarterly, vol. 43, nb. 3, pp. 211-220

Howard R. A., Speaking of Decisions: Precise Decision Language, Decision Analysis, 2004, vol. 1, nb.2, pp. $71-78$

Kato H. and Kosuda K., Elimination-by-Aspects in Urban Rail Demand Analysis, Traffic and Transportation Studies Congress, 2008

Keeney R.L. and Raiffa H., Decisions with Multiple Objectives: Preferences and Value Trade-offs. New York: Wiley, 1976

Khraibani R., A New Evaluation and Decision Making Framework Investigating the Elimination by Aspects Model in the Context of Transportation Projects' Investment Choices, $\mathrm{PhD}$ Thesis, 2012

Laurent R.A., 'Elimination by aspects' and probabilistic choice, PhD Thesis, 2006

Lippman D., Voting Theory, Creative Commons BY-SA (A summary document)

Luce R.D., Individual Choice Behavior: A Theoretical Analysis. New York: Wiley, 1959

Nellthorp J. and Mackie P.J., The UK Roads Review - a hedonic model of decision making, Transport Policy, 2000, vol. 7, pp. 127-138

Nurmi H., Voting Theory, Public Choice Research Centre and Department of Political Science, University of Turku (A summary document)

Priemus H. and Bert Van Wee, Public Planning of Large Rail Projects: Nightmare or Success Story?, Transportation Planning and Technology, February 2007, vol. 30, nb. 1, pp. 1-7 
Quinet E., Evaluation methodologies of transportation projects in France, Transport Policy, 2000, vol. 7 , pp. 27-34

Ranyard R.H., Elimination By Aspects as a decision rule for risky choice, Acta Psychologica, 1976, vol. 40, pp. 299-310

Restle F., Psychology of Judgment and Choice. New York: Wiley, 1961

Saaty, T.L., The Analytic Hierarchy Process. New York: McGraw-Hill, 1980

Salling K. B. and Banister D., Assessment of large transport infrastructure projects: the CBA-DK model, Transportation Research Part A, 2009, vol. 43, pp. 800-813

Sayers T.M., Jessop A.T. and Hills P.J., Multi-criteria evaluation of transport options - flexible, transparent and user-friendly?, Transport Policy, 2003, vol. 10, pp. 95-105

Sassoon 2010, in UK's Coalition Gov't Unveils 200B National Infrastructure Plan, by L. clapper accessed: http://www.constructiondigital.com/sectors/uk-s-coalition-gov-t-unveils-200b-national-infrastructure-plan

Simon H., A Behavioral Model of Rational Choice, The Quarterly Journal of Economics, February 1955, vol. 69 , nb. 1, pp. $99-118$

Short J., Kopp A., Transport infrastructure: Investment and planning. Policy and research aspects, Transport Policy, 2005, vol. 12, pp. 360-367

Small K., Working Paper, UCTC nb 379, The University of California Transportation Center, Revised October 1998

Tsamboulas D.A., A tool for prioritizing multinational transport infrastructure investments, Transport Policy, 2007, vol. 14, pp. 11-26

Tversky A., Elimination by aspects: A theory of choice, Psychological Review, 1972a, vol. 79, pp. 281299

Tversky A., Choice by Elimination, Journal of Mathematical Psychology, 1972b, vol. 9, pp. 341-367

Wang Y.M. and Luo Y., On rank reversal in decision analysis, Mathematical and Computer Modelling, 2009, vol. 49, nb. 5-6, pp. 1221-1229

Wickelmaier F. and Schmid C., A Matlab function to estimate choice model parameters from pairedcomparison data, Behavior Research Methods, Instruments, \& Computers, 2004, vol. 36, nb. 1, pp. 29-40

Young W., A non-tradeoff decision making model of residential location choice, TR-A, 1984, vol. 18, nb. $1-\mathrm{A}$

Young H. P., Condorcet's Theory of Voting, The American Political Science Review, 1988, vol. 82, nb. 4, pp. 1231-1244 
Zahid M. A., Majority Judgment Theory and Paradoxical Results, International Journal of Arts \& Sciences, 2011, CD-ROM, ISSN: 1944-6934: 4(20):121-131

\section{Glossary}

IRR: Internal Rate of Return

NPV: $\quad$ Net Present Value

E[NPV]: $\quad$ Expected Value of NPV

E[ENPV]: $\quad$ Expected Value of Economic NPV

SD: $\quad$ Standard Deviation

ID: $\quad$ Index of Dispersion

CVaR: $\quad$ Conditional Value-at-Risk

VaR: $\quad$ Value-at-Risk

NPV-at-Risk: equivalent to the VaR for the NPV

EBA: $\quad$ Elimination by Aspects

TEBA: $\quad$ Transportation EBA - a new evaluation and decision making framework proposed by the authors in this paper

PWC: $\quad$ Pairwise Comparison method - a method for estimating the parameters of an EBA model using pairwise choice information

ROW: $\quad$ Right-of-Way

HSR: $\quad$ High Speed Rail

TT: $\quad$ Travel Time

VOC: $\quad$ Vehicle Operating Cost 


\section{Appendix A - Index of Dispersion}

Before proceeding with the definition of the index of dispersion, a few definitions are in order.

A ranking is an ordering of the options referring to each option's position with respect to the others. A sequence is an ordering of the options where each option is located in its rank position. For instance, the ranking described as: option $\mathrm{B}$ is ranks first, option $\mathrm{A}$ ranks second and option $\mathrm{C}$ ranks last, results in the sequence $\mathrm{B} \succ \mathrm{A} \succ \mathrm{C}$. One could also refer to an option by a number (for example, option $\mathrm{A}$ is referred to as 1, option B as 2, etc...) and the position of the option indicates its ranking. So for the same example ranking, the resulting sequence can equivalently be expressed as $2 \succ 1 \succ 3$. This latter convention turns out useful for modeling purposes.

Each sequence/ranking of options has a probability of occurring, equal to the probability of each option in the sequence being selected out of a set that contains that option and all the options that rank lower than this option. For instance, the probability of sequence $\mathrm{B} \succ \mathrm{A} \succ \mathrm{C}$ occurring is equal to $\mathrm{p}=\mathrm{x} * \mathrm{y}$, where $\mathrm{x}$ is the probability of choosing Option B out of a group containing Options A, B and C, and y is the probability of choosing Option A out of the reduced set of options containing Options A and C. Arguments that the fact that $\mathrm{B} \succ\{\mathrm{A}, \mathrm{C}\}$ provides no information have arisen in advanced discussions on the topic. This is a difficult question that we do not deal with in this text. For a discussion of the matter please refer to de Palma and Kilani, 2015.

Our choice group contains 6 options, so there are 720 (which is 6!) possible sequences. For each sequence, the probability of occurrence can be calculated from the criteria weights estimated from the EBA model. A Matlab function was developed to calculate the probability of occurrence of each sequence and returns a vector with 720 probability values. These values sum to 1 .

Also, each sequence is different from another sequence by a certain number of 1 step moves. For instance, to go from sequence $2 \succ 4 \succ 1 \succ 3$ to $1 \succ 2 \succ 3 \succ 4$ the minimum number of 1 step moves is 3 . The number of 1 step moves is obviously an indicator of the "distance" that separates 2 sequences. This method was also used in de Palma, Picard and Ziegelmeyer (2011).

We define the Index of Dispersion for a given sequence (the tested sequence) for a given model as the sumproduct of the probability of a sequence in the set, as determined from the EBA model, and the number of steps required to get from this sequence to the tested sequence, over all possible sequences other than the tested sequence. Its value will reflect the likelihood of the tested sequence occurring. A low 
value for the index of dispersion indicates that the sequences with highest probabilities are the ones that are "closest" to the tested sequence. In fact, the more different a sequence is from the target sequence the higher the number of single steps to go from one to the other and the more it will penalize the index of dispersion. If the probability of this sequence is high and its number of steps is also high then there is a high penalty on the index of dispersion. If the probability of this sequence is low then the penalty is low. On the other hand, if the number of steps is low, that is the sequence is quite similar to the target one, and its probability is high, then that high probability will not have a large penalizing multiplier effect on the index of dispersion.

For the purpose of our work, the tested sequence is the one corresponding to the deterministic social aggregate ranking (DR). Based on the above discussion, the lower the index of dispersion of DR the more likely it is that the EBA model will return DR.

Since the absolute measure of the Index does not allow judgment on whether it is low enough, the relative magnitude of this Index with respect to Indices generated from all other sequences is contemplated.

In other words, sequentially, over all sequences, each sequence is set as the tested sequence and its Index of Dispersion is calculated. There are then 720 indices of dispersion each corresponding to a tested sequence. It is worth mentioning here that we consider a linear distance while we could also consider a quadratic one. The impact of using the latter is proposed as subject for further research. 


\section{Appendix B - Survey and Data Collection}

The survey was conducted online. The link to the survey was communicated to carefully selected groups of people through email. Follow-up emails were needed in many cases to ensure the proper administration of the survey. In-person meetings were also conducted to facilitate the process and ensure clarity. The importance of quality answers was emphasized with each individual taking the survey. This was a completely voluntary exercise which leads to belief there is no motive for respondents to provide subquality answers. A comments section at the end of the survey required survey takers to describe qualitatively their approach to decision making and contemplation of the answers to this section by the authors helped confirm the quality of the survey answers. Moreover, consistency of findings from analysis with the state of the literature particularly with regards to criteria preferences by various groups of stakeholders confirms the good quality of the answers.

In the case of the public sector (Group 1), the sub-groups included:

- Members of parliament, Members of parliament and members of infrastructure chamber, Current and former Ministers, Executives in the Ministry of Transportation, Other politicians,

- Advisors to politicians including Ministers and other, Private advisors to the Ministry of Transportation, i.e consulting firms supporting the public sector

- Graduate students (mostly Economics and Civil Engineering students and graduates) at major local and international universities who will potentially pursue careers in public sector advising

In the case of the private party (Group 2), the sub-groups included:

- Professional decision makers in large infrastructure conglomerates

- $\quad$ MBA students and graduates at top-tier universities

- Professional decision making advisors from top Management and Strategy Consulting Firms

The "People's Committee"/General Public (Group 3) included:

- Graduate students at top universities in Lebanon in the domains of

$\circ$ Engineering management

- Business administration

$\circ$ Civil engineering

- Lebanese transportation engineers and planners 
The survey was conducted from the beginning of July to the end of September. The distribution of responses, including the number of people contacted, those who started but did not finish completing the survey, those who finished and those who provided enough useful information came out as presented in Table B-1 across groups:

Table B-1 - Survey Data: Distribution of Responses; the number of people contacted, those who accessed the survey, those who provided useful information and those who completed the full survey are reported.

\begin{tabular}{|l|c|c|c|}
\cline { 2 - 4 } \multicolumn{1}{c|}{} & \multicolumn{3}{|c|}{ Group } \\
\cline { 2 - 4 } \multicolumn{1}{c|}{} & Public & Private & General \\
\hline Approx. Nb. Contacted & 120 & 150 & 100 's \\
\hline Nb. Who Accessed the Survey & 59 & 54 & 63 \\
\hline $\begin{array}{l}\text { Nb. Who Provided Useful Data but did not Fully } \\
\text { Complete Taking the Survey }\end{array}$ & 48 & 45 & 38 \\
\hline Nb. Who Completed Taking the Survey & 40 & 36 & 34 \\
\hline Total Number of Useful Answers & $\mathbf{4 8}$ & $\mathbf{4 5}$ & $\mathbf{3 8}$ \\
\hline \hline Final Total Number of Useful Answers & & 131 & \\
\hline
\end{tabular}

Further details regarding survey tools and processes as well as the architecture of data collection and processing are presented in Figures B-1 and B-2. 
The Survey: Interview Tool and Process

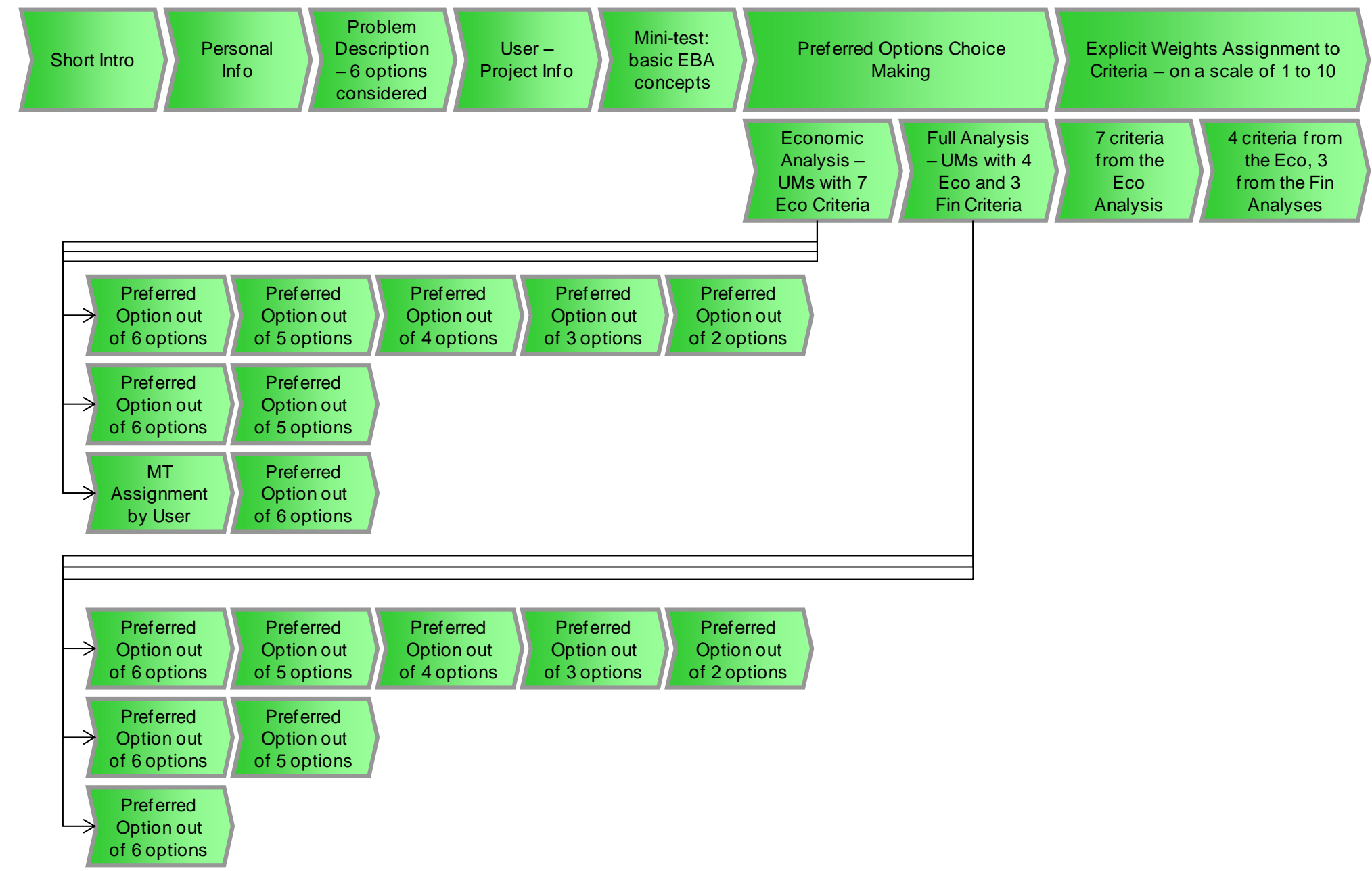

Figure B-1 - Web-Survey Steps; depicts the different sections of the survey and the steps that the respondent goes through in the process for the Example of the Public Sector Site 


\section{Data collection and description of data}

The architecture of the data input from the web-survey looks as shown in the figure below:

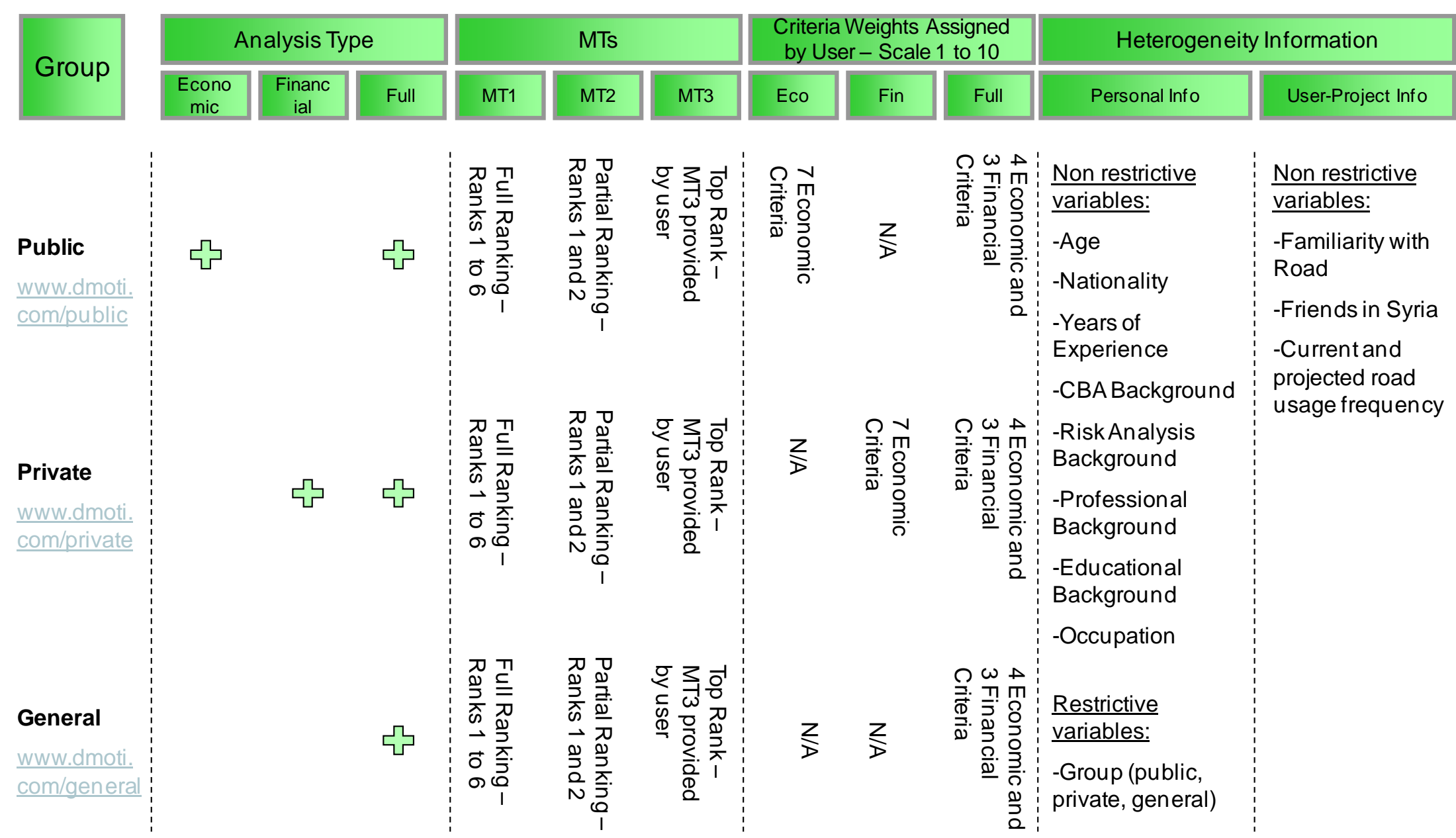

Figure B-2 - Survey Design: Architecture of Data Input; includes the analysis types, MTs, Criteria weights' assignment, personal information and user/project information collected for each version of the site, the one for the Public Sector, the one for the Private Sector and the one for the General Public 